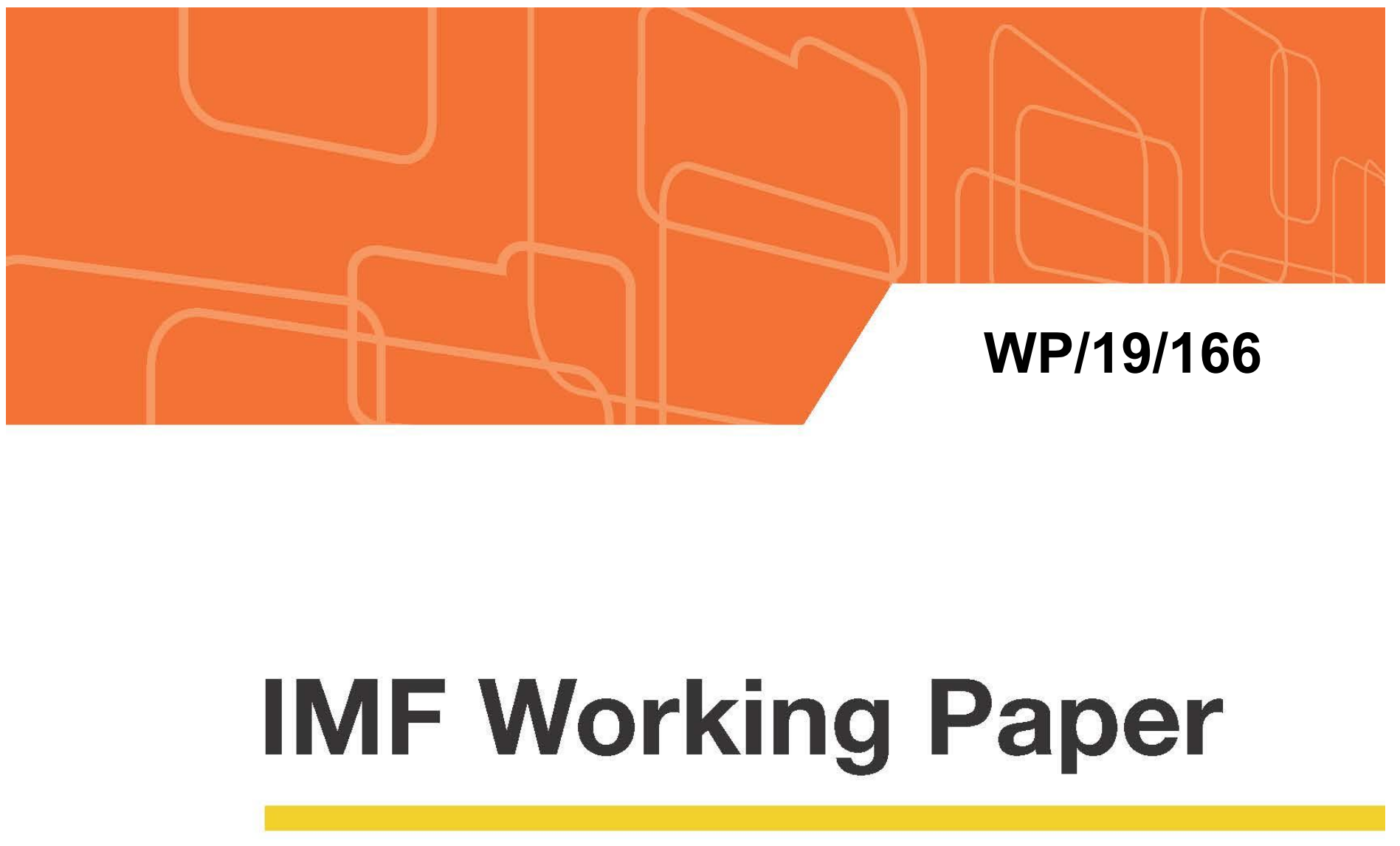

\title{
Optimal Monetary Policy under Bounded Rationality
}

by Jonathan Benchimol and Lahcen Bounader

IMF Working Papers describe research in progress by the author(s) and are published to elicit comments and to encourage debate. The views expressed in IMF Working Papers are those of the authors and do not necessarily represent the views of the IMF, its Executive Board, or IMF management. 


\title{
IMF Working Paper
}

Middle East and Central Asia Department

\section{Optimal Monetary Policy under Bounded Rationality}

\section{Prepared by Jonathan Benchimol and Lahcen Bounader ${ }^{1}$}

Authorized for distribution by Subir Lall

August 2019

\begin{abstract}
IMF Working Papers describe research in progress by the authors and are published to elicit comments and to encourage debate. The views expressed in IMF Working Papers are those of the authors and do not necessarily represent the views of the IMF, its Executive Board, or IMF management.
\end{abstract}

\begin{abstract}
The form of bounded rationality characterizing the representative agent is key in the choice of the optimal monetary policy regime. While inflation targeting prevails for myopia that distorts agents' inflation expectations, price level targeting emerges as the optimal policy under myopia regarding the output gap, revenue, or interest rate. To the extent that bygones are not bygones under price level targeting, rational inflation expectations is a minimal condition for optimality in a behavioral world. Instrument rules implementation of this optimal policy is shown to be infeasible, questioning the ability of simple rules à la Taylor (1993) to assist the conduct of monetary policy. Bounded rationality is not necessarily associated with welfare losses.

JEL Classification Numbers: C53, E37, E52, D01, D11.

Keywords: monetary policy, myopia, commitment, discretion, optimal simple rules.

Author's E-Mail Address: jonathan.benchimol@boi.org.il and lbounader@imf.org

\footnotetext{
${ }^{1}$ The views expressed in this paper are those of the authors and do not necessarily represent the views of the Bank of Israel or the International Monetary Fund. The authors thank Itai Agur, Olivier Blanchard, Mátyás Farkas, Jorge Ivan Canales Kriljenko, Xavier Gabaix, Lars Peter Hansen, Ori Heffetz, Seppo Honkapohja, Doron Kliger, Subir Lall, Luca Onorante, Johannes Pfeifer, John Roberts, Guy Segal, Michel Strawczynski, participants at the 2nd CEPR MMCN Annual Conference at Stanford University, and participants at the Hebrew University of Jerusalem, the Bank of Israel, the Bank of Finland and the Bucharest University of Economic Studies research seminars for their useful comments.
} 


\section{Introduction}

There is broad agreement that the rational expectations hypothesis falls short in capturing the complex dynamics between monetary policy decisions and agents' anticipations. There is less agreement on the appropriate deviation from this hypothesis to investigate monetary policy questions. Overall, the optimal monetary policy conclusions from the rational inattention or learning literature are the same as in the rational model or, at best, slightly deviate without altering the way monetary policy should be conducted. Our new insights about the dependence of optimal monetary policy on specific myopia ${ }^{1}$ characterizing households and firms, as well as their practical implications for monetary policy conduct, contribute to this debate.

Optimal monetary policy is widely analyzed in the literature through New Keynesian models (Clarida et al., 1999; Woodford, 2003), which emphasize that agents' expectations about the future are rational and somehow perfect. According to Blanchard (2009, 2018), this assumption is exaggerated and quite far from reality, even when considering aggregated representative agents. Who knows what the inflation rate will be next month? What will the output gap be next quarter? Who looks at every macroeconomic variable when deciding about consumption? Even perfectly informed people are not acting that way. Despite this caveat, academics and practitioners consider this model to be the workhorse for monetary policy analysis and its conclusions still shape the monetary economics literature. ${ }^{2}$

In this paper, we extend the New Keynesian model to account for agent's inattentiveness to macroeconomic variables. Since agent's expectations are bounded (Andrade and Le Bihan, 2013; Coibion and Gorodnichenko, 2015; Gennaioli et al., 2016), we relax the rationality assumption in favor of bounded rationality, whereby agents are assumed to be partially myopic and unable to anticipate macroeconomic developments perfectly (Akerlof and Yellen, 1987). Bringing non-rational elements to New Keynesian models to highlight their impact on optimal monetary policy prescriptions is essential for policymakers. In addition to offering a rich set of policies to the central bank, this model provides the policymaker with a realistic tool to communicate their policies to real (non-rational) economic agents. Households and firms' bounded rationality leads policymakers to question the optimality of monetary policy under such forms of inattention. ${ }^{3}$

\footnotetext{
${ }^{1}$ The terms myopia, inattention, and bounded rationality are used interchangeably in this paper.

${ }^{2}$ As Stiglitz (2011) notes, one crucial underlying assumption of the traditional models is rational behavior of the economy, but the real-world economy seems inconsistent with any model of rationality.

${ }^{3}$ Our framework assumes the central bank behaves rationally. By optimizing behavioral agents, for our research question, a behavioral central bank is not necessary.
} 
Inspired by the bounded rationality approach of Gabaix (2019) but departing from his model and calibration, we derive optimal monetary policy results under differentiated forms of myopia that complement the latter. ${ }^{4}$ While the transition from subjective to objective expectations we use is realistic, the general production function we use for the representative firm lead to substantial differences in the trade-off between output and inflation, changing the amplitude of the central bank's reaction to cost-push shocks. ${ }^{5}$ Our study of optimal monetary policy is conducted through a welfare-relevant behavioral New Keynesian model, ${ }^{6}$ which allows a model-consistent welfare criterion. Optimal monetary policy in a fully microfounded behavioral New Keynesian dynamic stochastic general equilibrium framework, using a second-order approximation of the household's utility, is assessed. The first- and second-best equilibria under commitment and discretion, respectively, are examined. The possibility that an optimal simple rule implements the first best solution is analyzed. All these configurations are explored through variants of the behavioral New Keynesian model emphasizing the output gap, interest rate, inflation, revenue, general or full myopia.

This paper is related to several strands of the literature. First, it extends the monetary economics literature (Clarida et al., 1999; Woodford, 2003; Galí, 2015) by relaxing the rational expectation hypothesis. Second, compared to the learning (Evans and Honkapohja, 2012, 2013; Woodford, 2013) or the rational inattention (Sims, 2003; Maćkowiak and Wiederholt, 2009, 2015) literature, it provides an alternative way to deviate from the rational expectation hypothesis while providing richer policy conclusions. Third, based on Gabaix (2014), it extends the optimal monetary policy literature.

Our finding challenges existing conclusions about optimal monetary policy under rational expectations as well as under bounded rationality-including rational inattention and learning-in the literature. The policy conclusion from our behavioral framework complements and enriches the existing literature. We show that bounded rationality has essential implications for the conduct of monetary policy and emphasize the central result of our paper that IT or PLT could be both (behaviorally) optimal under different circumstances and bounded rationality extensions. Previous literature has shown that the optimal policy resulting from the rational

\footnotetext{
${ }^{4}$ Here, bounded rationality means an agent's myopia to variables of interest in its decisionmaking. The plausibility of this approach finds its roots in the work of Kahneman (1973), who attributes attention to effort and inattention, by deduction, to laziness. Consequently, it is more convenient to model Homo sapiens as myopic agents. The key novelty of this paper, that agents can be myopic about specific economic variables, is discussed in Section 3.1.

${ }^{5}$ While our qualitative results do not hinge on this assumption, it modifies the amplitude of the interest rate responses to shocks.

${ }^{6}$ Normative analysis with exogenous myopia parameters is made possible by relying on the local rigidity property explained in Section 3.1.
} 
New Keynesian framework recommends a form of price level targeting (PLT), while rational inattention finds small differences in terms of welfare compared to the rational case, which does not alter the policy conclusions (Maćkowiak and Wiederholt, 2015). Learning models as surveyed in Eusepi and Preston (2018) convey the conclusion that a form of PLT could be an adequate proxy of the optimal policy response. However, Gabaix (2019) finds that PLT is suboptimal with behavioral agents. We challenge these previous results by showing that PLT is optimal when assuming some forms of bounded rationality, particularly those not involving macroeconomic inattention to inflation, while it is suboptimal in other cases. Under PLT, bygones are not bygones, which requires awareness (rationality) from the public regarding inflation developments.

On the practical side, we find that simple instrument rules, such as Taylor (1993), its variations, price level or nominal GDP (NGDP) rules, are unable to implement the optimal policy path. This result calls for the adoption of targeting rules in the sense of Woodford $(2003,2010)$ as a practical guideline for optimal monetary policy conduct. Such a proposal was made long ago by Svensson (2003). Our result can be seen as a formal proof of the shortsightedness of mechanical simple rules in the policymaking process, especially in a behavioral world.

Additionally, we find that bounded rationality is not necessarily associated with decreased welfare. Several forms of economic inattention, especially extreme ones, can increase welfare. By contrast, output gap myopia implies significant welfare losses compared to the rational case. The appropriate response from the central bank to economic disturbances improves the social welfare of behavioral agents.

The remainder of the paper is organized as follows. Section 2 describes the behavioral New Keynesian model, and Section 3 outlines the methodology used for the study of optimal monetary policy. Section 4 and Section 5 present the optimal monetary policy under commitment and discretion, respectively. Section 6 characterizes optimal simple rules and weights within the same model. Section 7 interprets and discusses our findings to draw some policy implications in Section 8. Section 9 presents the concluding remarks, and Section 10 presents our derivations and robustness checks.

\section{The model}

Our model is based on the psychological foundations of bounded rationality brought by Gabaix (2014, 2019), among others (De Grauwe, 2012; Evans and Honkapohja, 2013; Woodford, 2013), to macroeconomic analysis. In this framework, agents' representations of the economy are sparse, i.e., when they optimize, agents care 
only about a few variables that they observe with some myopia.

Departing from Gabaix (2019), our model assumes decreasing returns to scale and different types of myopia other than general myopia. This framework will serve later on to assess optimal monetary policy under different policy designs: discretion, commitment, and optimal simple rules.

\subsection{Households}

The infinitely lived rational representative household's utility is

$$
U\left(c_{t}, N_{t}\right)=\frac{c_{t}^{1-\gamma}-1}{1-\gamma}-\frac{N_{t}^{1+\phi}}{1+\phi}
$$

where $c_{t}$ is real consumption and $N_{t}$ is labor supply. $\gamma$ is the coefficient of the household's relative risk aversion, i.e., the inverse of the intertemporal elasticity of substitution, and $\phi$ is the inverse of the Frisch elasticity of labor supply, i.e., the inverse of the elasticity of work effort with respect to the real wage.

The household maximizes

$$
\mathbb{E}_{0} \sum_{t=0}^{\infty} \beta^{t} U\left(c_{t}, N_{t}\right)
$$

where $\mathbb{E}$ is the usual expectation operator and $\beta$ is the static discount factor subject to the wealth dynamics

$$
k_{t+1}=\left(1+r_{t}\right)\left(k_{t}-c_{t}+y_{t}\right)
$$

and the real income as

$$
y_{t}=w_{t} N_{t}+y_{t}^{f}
$$

where $k_{t}$ is the household's wealth, $r_{t}$ the real interest rate, $y_{t}$ the agent's real income, $w_{t}$ the real hourly wage, $N_{t}$ the worked hours, and $y_{t}^{f}$ the profit income.

The rational household's problem is to maximize its period utility (Eq. 2) subject to its wealth evolution (Eq. 3).

The behavioral household maximizes the same lifetime utility (Eq. 2) but does not pay full attention to all variables in the budget constraints, as correctly processing information entails a cost. The behavioral agent perceives reality with some myopia, which is associated with this information cost.

Let $\hat{r}_{t}=r_{t}-\bar{r}$ and $\hat{y}_{t}=y_{t}-\bar{y}$ be the deviations of real interest rate and output, respectively, from their steady state. Following Gabaix (2019), the behavioral agent's inattention is associated with perceived deviations from the steady-state 
real interest rate, $\hat{r}_{t}^{B R}=\hat{r}^{B R}\left(S_{t}\right)$, the function of the current state vector of the economy $S_{t}$, and real income, $\hat{y}_{t}^{B R}=\hat{y}^{B R}\left(N_{t}, S_{t}\right)$.

The behavioral agent's budget constraint becomes

$$
k_{t+1}=\left(1+\bar{r}+\hat{r}^{B R}\left(S_{t}\right)\right)\left(k_{t}-c_{t}+\bar{y}+\hat{y}^{B R}\left(N_{t}, S_{t}\right)\right)
$$

where $\hat{r}^{B R}\left(S_{t}\right)=m_{r} \hat{r}_{t}\left(S_{t}\right)$ and $\hat{y}^{B R}\left(N_{t}, S_{t}\right)=\hat{y}^{B R}\left(S_{t}\right)+w_{t}\left(N_{t}-N\left(S_{t}\right)\right)$.

$\hat{y}^{B R}\left(N_{t}, S_{t}\right)$ is the perceived personal income while $\hat{y}^{B R}\left(S_{t}\right)=m_{y} \hat{y}_{t}\left(S_{t}\right)$ is the aggregate income. The equation of the perceived income indicates that the behavioral agent perceives only a fraction of the aggregate income but perfectly perceives his marginal income.

Note that $m_{r}$ and $m_{y}$ are myopia parameters ${ }^{7}$ in $[0,1]$. For $m_{r}=m_{y}=1$, the rational household's budget constraint is recovered. Separately, $m_{r}$ is the real interest rate myopia, and $m_{y}$ is the real income myopia.

The future state vector of the whole economy populated by rational agents evolves as

$$
S_{t+1}=f\left(S_{t}, \epsilon_{t+1}\right)
$$

where $f$ is a function of the current state vector of the economy ${ }^{8}$ and an innovation process vector in the next period, $\epsilon_{t+1}$.

The future state vector of the whole economy populated by behavioral agents evolves as

$$
S_{t+1}=\bar{m} f\left(S_{t}, \epsilon_{t+1}\right)
$$

where $\bar{m} \in[0,1]$ represents the general myopia of the agent regarding the economy's state. When $\bar{m}=1$, the rational agent's law of motion (Eq. 6) is recovered.

Consequently, the problem of the behavioral household consists of maximizing the period utility (Eq. 2) subject to the behavioral wealth (Eq. 5) and the behavioral state vector of the economy (Eq. 7).

By clearing the goods market, in which output is equated with consumption $y_{t}=c_{t}$, and solving the household's problem with respect to $c_{t}$, the behavioral IS equation ${ }^{9}$ becomes

$$
\tilde{y}_{t}=M \mathbb{E}_{t}\left[\tilde{y}_{t+1}\right]-\sigma\left(i_{t}-\mathbb{E}_{t}\left[\pi_{t+1}\right]-r_{t}^{n}\right)
$$

where $\tilde{y}_{t}$ is the output gap expressed as deviations of output from its natural level, $i_{t}$ is the nominal interest which links to $r_{t}$ by the Fisher equation, $r_{t}^{n}$ is the natural level of the real interest rate, $M=\bar{m} /\left(R-m_{Y} \bar{r}\right), \sigma=m_{r} /\left(\gamma R\left(R-m_{Y} \bar{r}\right)\right)$ where

\footnotetext{
${ }^{7}$ See Section 3.1 for more details about these parameters.

${ }^{8}$ The function $f$ may contain technological shocks, fiscal measures, etc.

${ }^{9}$ See Appendix A.1 for a detailed derivation of the IS curve (Eq. 8).
} 
$m_{Y}=\left(\phi m_{y}+\gamma\right) /(\phi+\gamma)$ and $R=1+\bar{r}=1 / \beta$ and $\bar{r}$ is the steady state of the real interest rate.

The First-Order Condition (FOC) with respect to $N_{t}$ is

$$
w_{t}=\gamma c_{t}+\phi n_{t}
$$

where $n_{t}$ is the log deviation of employment, $N_{t}$, from its steady state.

The rational IS curve obtained as a particular case, when $m_{r}=m_{y}=\bar{m}=1$, is

$$
\tilde{y}_{t}=\mathbb{E}_{t}\left[\tilde{y}_{t+1}\right]-\sigma_{r e}\left(i_{t}-\mathbb{E}_{t}\left[\pi_{t+1}\right]-r_{t}^{n}\right)
$$

where $\sigma_{r e}=1 /(\gamma R)$.

By comparing the behavioral (Eq. 8) and the rational (Eq. 10) IS curves, ${ }^{10}$ the future output appears to have less influence on current output in the behavioral equation $(M<1)$. Moreover, the transmission of monetary policy to the real economy is stronger in the rational than in the behavioral case $\left(\sigma_{r e} \geq \sigma\right)$.

\section{$2.2 \quad$ Firms}

A continuum of firms populates our economy. Each firm $i$ produces differentiated goods using the same technology described by

$$
Y_{t}(i)=A_{t} N_{t}(i)^{1-\alpha}
$$

where $A_{t}$ is the technological factor (identical across all firms) that evolves such that $a_{t}=\rho_{a} a_{t-1}+\varepsilon_{t}^{a}$, where $a_{t}=\ln A_{t}$ and $\varepsilon_{t}^{a} \sim N\left(0 ; \sigma_{a}\right)$, i.i.d. over time, and $N_{t}(i)$ are the worked hours at firm $i$, which aggregates as $N_{t}=\int_{0}^{1} N_{t}(i) d i$.

Note that unlike Gabaix (2019), we assume decreasing returns to scale $(\alpha>0)$, allowing our inflation dynamics to depend on the elasticity of substitution between different goods, $\varepsilon$. Assuming constant returns to scale $(\alpha=0)$ in the production function removes the role of this elasticity of substitution in the Phillips curve. ${ }^{11}$

Following Galí (2015), firms face Calvo (1983) pricing frictions and adjust their prices in each period with probability $1-\theta$. The optimal price setting of the firm, $P_{t}^{*}$, is the price that maximizes the current market value of the profits generated while that price remains effective.

\footnotetext{
${ }^{10}$ To obtain the rational version of the IS equation (Eq. 10), the reader is invited to expand Eq. 41 in Appendix A.1, as we do for the behavioral case.

${ }^{11}$ As presented below, this elasticity plays an essential role in the Phillips curve (Eq. 15). Decreasing return to scale also allows us to provide complete robustness checks (Appendix B.1).
} 
The problem of the behavioral firm is to maximize

$$
\sum_{k=0}^{\infty} \theta^{k} \mathbb{E}_{t}^{B R}\left[\Lambda_{t, t+k}\left(P_{t}^{*} Y_{t+k \mid t}-\Psi_{t+k}\left(Y_{t+k \mid t}\right)\right)\right]
$$

subject to the sequence of demand constraints

$$
Y_{t+k \mid t}=\left(\frac{P_{t}^{*}}{P_{t+k}}\right)^{-\varepsilon} Y_{t+k}
$$

where behavioral agents have a subjective expectation ${ }^{12}$ denoted by the operator $\mathbb{E}_{t}^{B R}[],. \Lambda_{t, t+k}=\beta^{k}\left(c_{t+k} / c_{t}\right)^{-\gamma}\left(P_{t+k} / P_{t}\right)$ is the stochastic discount factor in nominal terms, $\Psi_{t+k}($.$) is the cost function, Y_{t+k \mid t}$ is the output in period $t+k$ for a firm that last reset its price in period $t, P_{t}^{*}$ is the optimal price the behavioral firm seeks to determine and $P_{t}$ is the price level of the overall economy.

Expanding the FOC of the firm's problem around the zero-inflation steady state $^{13}$ yields

$$
p_{t}^{*}-p_{t-1}=(1-\beta \theta) \sum_{k \geq 0}(\beta \theta)^{k} \mathbb{E}_{t}^{B R}\left[\widehat{m c}_{t+k \mid t}+p_{t+k}-p_{t-1}\right]
$$

where $\widehat{m c}_{t+k \mid t}$ is the deviation of the real marginal cost, $m c_{t+k \mid t}=\ln \frac{\Psi_{t+k}^{\prime}\left(Y_{t+k \mid t}\right)}{P_{t+k}}$, in $t+k$ of a firm that last reset its price at $t$ from its steady state value $m c=-\ln \frac{\varepsilon}{\varepsilon-1}$.

The resulting behavioral Phillips curve is ${ }^{14}$

$$
\pi_{t}=\beta M^{f} \mathbb{E}_{t}\left[\pi_{t+1}\right]+\kappa \tilde{y}_{t}
$$

where $M^{f}=\theta \bar{m} /\left(1-(1-\theta) m_{\pi}^{f}\right)$ and $\kappa=\frac{(1-\theta)(1-\beta \theta) m_{x}^{f}}{1-(1-\theta) m_{\pi}^{f}} \Theta\left(\gamma+\frac{\phi+\alpha}{1-\alpha}\right)$, in which $\Theta=(1-\alpha) /(1-\alpha+\alpha \epsilon) \cdot m_{x}^{f}$ and $m_{\pi}^{f}$ represent the perfect foresight fraction by the firm of the future marginal $\operatorname{cost}^{15}$ and inflation, respectively.

Assuming constant return to scale ${ }^{16}$ affects the core optimal monetary policy analysis, which depends on the trade-off between inflation and the output gap, $\kappa$. In our Phillips curve (Eq. 15), the coefficient $\kappa$ depends on $\alpha$, the decreasing return to scale parameter.

Interestingly, $\frac{\partial \kappa}{\partial \alpha}=m_{x}^{f} \Phi<0$, where $\Phi=\frac{(1-\beta \theta)(1-\theta)(\phi+1-(\gamma+\phi) \epsilon)}{(\alpha \epsilon-\alpha+1)^{2}}$, i.e. $\kappa$ is decreasing with $\alpha$.

\footnotetext{
${ }^{12}$ See Appendix A.1 for the definition of this subjective expectation operator.

${ }^{13}$ See Eq. 50 in Appendix A.2 for further details.

${ }^{14}$ See Appendix A.2 for detailed derivations.

${ }^{15}$ By extension, as it proportionally enters $\kappa$, we recall this marginal cost myopia an output gap myopia.

${ }^{16} \mathrm{Or}$, in other words, $\alpha=0$ in the production function (Eq. 11).
} 
Another interesting observation about $\alpha$ concerns its relationship with the output gap weight in the microfounded loss function, ${ }^{17} w_{x} / w_{\pi}$. As $\frac{\partial w_{x} / w_{\pi}}{\partial \alpha}=\frac{1}{\theta \epsilon} \Phi<0$, $w_{x} / w_{\pi}$ is a decreasing function of $\alpha$. Consequently, the central bank gives less attention to the output gap objective when $\alpha$ increases.

The rational Phillips curve, obtained by assuming $m_{x}^{f}=m_{\pi}^{f}=\bar{m}=1$, is

$$
\pi_{t}=\beta \mathbb{E}_{t}\left[\pi_{t+1}\right]+\kappa_{r e} \tilde{y}_{t}
$$

where $\kappa_{r e}=\frac{(1-\theta)(1-\beta \theta)}{\theta} \Theta\left(\gamma+\frac{\phi+\alpha}{1-\alpha}\right)$.

The first contrast between the behavioral (Eq. 15) and the rational (Eq. 16) Phillips curves is the weight of future inflation in the determination of current inflation. This weight is more attenuated in the behavioral than in the rational equation (as $M^{f}<1$ ). Second, the sensitivity of inflation to the output gap in the rational model is greater than that in the behavioral model (as $\kappa_{r e}>\kappa$ ).

Note that Gabaix (2019) derived a similar Phillips curve, at least in its functional form: inflation depends on its expectations as well as on the output gap. The only difference is related to the magnitude of the feedback from each variable to inflation. The feedback coefficients from Gabaix (2019) are as follows

$$
\begin{gathered}
M_{G}^{f}=\bar{m}\left(\theta+\frac{1-\beta \theta}{1-\beta \theta \bar{m}} m_{\pi}^{f}(1-\theta)\right) \\
\kappa_{G}=m_{x}^{f} \frac{(1-\theta)(1-\beta \theta)}{\theta}(\gamma+\phi)
\end{gathered}
$$

Eq. 17 and Eq. 18 highlight two substantial differences.

First, the main difference between $M^{f}$ (Eq. 15) and $M_{G}^{f}$ consists of the use of the term structure of expectations. In our formulation, $M^{f}$, we use the term structure of expectation starting from Eq. 58, while Gabaix (2019) used the same formula starting from Eq. 57 in the Appendix A.2. Our formulation is consistent with the term structure of expectations stipulated in Lemma 2.6 in Gabaix (2019). Unlike the level of the variable, its deviation from the steady state should be the argument for the term structure of the expectations. This correct transition from subjective to objective expectations explains why the Phillips Curve in Gabaix (2019) is not nested in our formulation.

Second, the difference between $\kappa$ (Eq. 15) and $\kappa_{G}$ is related to our assumption of decreasing returns to scale in the production function. Gabaix (2019) assumes constant return to scale, $\alpha=0$, which simplifies to $\kappa_{G}$. Although this assumption may seem irrelevant, we noticed that $\kappa$ is a function of $\alpha$ in our formulation and, more importantly, that $\kappa$ is decreasing with $\alpha\left(\frac{\partial \kappa}{\partial \alpha}<0\right)$. In other words, the de-

\footnotetext{
${ }^{17}$ The formal definitions of $w_{x}$ and $w_{\pi}$ are available in Section 3.3.
} 
creasing return to scale assumption might lengthen the feedback from real variables to nominal variables.

In addition to being more realistic, assuming a decreasing return to scale allows a role for inflation myopia $\left(m_{\pi}^{f}\right)$ in $\kappa$ that is nonexistent in $\kappa_{G}$. When $\kappa$ is decreasing with $\alpha$ in the general case $(\alpha \neq 0)$, the feedback from output to inflation is incomplete, and the central bank gives less weight to the output gap objective, compared to the constant return to scale $(\alpha=0)$ case. Then monetary policy should be more aggressive in bringing down inflation. This intuition will be clear from the robustness check section $\mathrm{B}$ when comparing the general case to the constant return to scale $(\alpha=0)$ calibration.

Our microfounded Phillips curve (Eq. 15) reflects the importance of both general myopia $(\bar{m})$ and inflation myopia $\left(m_{\pi}^{f}\right)$ in the weight of inflation expectations in the current inflation determination, which is also the case in Gabaix (2019). Moreover, our Phillips curve gives a role to inflation myopia $\left(m_{\pi}^{f}\right)$ in the weight of the output gap in the determination of current inflation, which is not the case in Gabaix (2019).

\subsection{Welfare-relevant model}

In the presence of nominal rigidities alongside real imperfections, the flexible price equilibrium is inefficient (Galí, 2015). Consequently, it is not optimal for the central bank to target this allocation, but it is optimal to target efficient allocation. Our model has to be expressed in terms of deviations with respect to the efficient aggregates so that the resulting variables become welfare-relevant ones.

Let us define the welfare-relevant output gap such that $x_{t}=y_{t}-y_{t}^{e}$, where $y_{t}$ is the (log) output, $y_{t}^{e}$ is the efficient output and $y_{t}^{n}$ is the natural output (flexibleprice output). Since $\tilde{y}_{t}=y_{t}-y_{t}^{n}$, linking the output gap and the welfare-relevant output gap gives $\tilde{y}_{t}=x_{t}+\left(y_{t}^{e}-y_{t}^{n}\right)$.

By exploiting this relationship, the behavioral IS curve in welfare-relevant output gap terms is

$$
x_{t}=M \mathbb{E}_{t} x_{t+1}-\sigma\left(i_{t}-\mathbb{E}_{t}\left[\pi_{t+1}\right]-r_{t}^{e}\right)
$$

where $r_{t}^{e}=r_{t}^{n}+(1 / \sigma)\left(M \mathbb{E}_{t}\left[y_{t+1}^{e}-y_{t+1}^{n}\right]-\left(y_{t}^{e}-y_{t}^{n}\right)\right)$ is the efficient interest rate perceived by households. ${ }^{18}$

The behavioral Phillips curve in welfare-relevant output gap terms is

$$
\pi_{t}=M^{f} \mathbb{E}_{t}\left[\pi_{t+1}\right]+\kappa x_{t}+u_{t}
$$

where $M^{f}=\frac{\beta \theta \bar{m}}{1-(1-\theta) m_{\pi}^{f}}$ and $\kappa=\frac{(1-\theta)(1-\beta \theta) \Theta m_{x}^{f}}{1-(1-\theta) m_{\pi}^{f}}\left(\gamma+\frac{\phi+\alpha}{1-\alpha}\right)$, and $u_{t}=\kappa\left(y_{t}^{e}-y_{t}^{n}\right)$ is a

\footnotetext{
${ }^{18}$ See Appendix A.4 for technical details.
} 
cost-push shock evolving according to an $A R(1)$ process such that $u_{t}=\rho_{u} u_{t-1}+\varepsilon_{t}^{u}$ and $\varepsilon_{t}^{u} \sim N\left(0 ; \sigma_{u}\right)$, i.i.d. over time.

The expectations in Eq. 19 and Eq. 20 are augmented by $M$ and $M^{f}$, respectively, thus reducing the exaggerated weight given to expectations in the rational New Keynesian model (Blanchard, 2009).

\section{Methodology}

\subsection{Myopia parameters}

As optimal monetary policy is fully microfounded, our research question is independent of the determination of the myopia parameters. They are thereby considered exogenous but in the interval $[0,1]$ as in Gabaix (2019). The endogenous case may be obtained by specifying cost functions for the agents, but we leave the myopia endogenization specification for further research.

Gabaix (2014) argues that inattention is derived from information's cost minimization, which yields to myopia parameters in the interval $[0,1]$. By construction, New Keynesian models have to obey some heuristics, like convergence and stability, implying that the framework may not support all irrationality forms, such as overattention, which is behaviorally plausible. Knowing these limitations, this type of model is preferred because of its tractability.

Although our model only focuses on under-reaction, it is also able to generate over-reaction (indirectly). As raised in Gabaix (2014), neglecting mitigating factors (i.e., negatively correlated additional effects) leads to overreaction. In other words, a consumer overreacts to an income shock if he pays too little attention to the fact that this shock is very transitory.

An essential feature of our theoretical framework allows for differentiated myopiathe fact that agents can be myopic about some economic variables. Wagner (1976) and Oates (1991) documented the revenue myopia as a consequence of several factors such as the complexity of the tax structure, the renter illusion with respect to property taxation, the income elasticity of the tax structure, the debt illusion, and the flypaper effect. Modigliani and Cohn (1979) have shown that because agents do not understand the real effect of raising prices on interest rates, the market's response to inflation is not rational. Bachmann et al. (2015) have found that spending attitudes are influenced by their nominal interest rate myopia. Other biases justify the adoption of differentiated myopia for our theoretical framework. 


\subsection{Calibration}

Our main experiment uses calibrated values at $15 \%$ of myopia, corresponding to a calibration of the myopia parameters at 0.85 . The detailed calibration for each model is described in Table 1 . The robustness analysis using higher and extreme values for myopia parameters to demonstrate that our conclusions hold is available in Appendix B.

\begin{tabular}{ccccccccc} 
& \multicolumn{7}{c}{ Models } \\
\cline { 2 - 7 } & No myopia & \multicolumn{7}{c}{ Myopia } \\
\cline { 2 - 7 }$m_{r}$ & Rational & & Interest rate & Output gap & Inflation & Revenue & General & Full \\
$m_{x}^{f}$ & 1 & & 0.85 & 1 & 1 & 1 & 1 & 0.85 \\
$m_{\pi}^{f}$ & 1 & 1 & 0.85 & 1 & 1 & 1 & 0.85 \\
$m_{y}$ & 1 & 1 & 1 & 0.85 & 1 & 1 & 0.85 \\
$\bar{m}$ & 1 & 1 & 1 & 1 & 0.85 & 1 & 0.85 \\
& 1 & 1 & 1 & 1 & 1 & 0.85 & 0.85
\end{tabular}

Table 1: Calibration of the myopia parameters used for the simulation of each model.

Table 2 summarizes the values used to simulate our regimes. The standard parameters of our model are calibrated as in Galí (2015). Several robustness checks using various calibrations from the New Keynesian literature are presented in Appendix B.

\begin{tabular}{|c|c|c|}
\hline Parameter & Calibration & Description \\
\hline$\beta$ & 0.996 & Static discount factor \\
\hline$\gamma$ & 2 & Household's relative risk aversion \\
\hline$\varepsilon$ & 9 & Elasticity of substitution between goods \\
\hline$\alpha$ & $1 / 3$ & Return to scale \\
\hline$\phi$ & 5 & Frisch elasticity of labor supply \\
\hline$\theta$ & 0.75 & Probability of firms not adjusting prices \\
\hline$\rho_{a}$ & 0.75 & Technology shock persistence \\
\hline$\rho_{u}$ & 0.75 & Cost-push shock persistence \\
\hline
\end{tabular}

Table 2: Calibration of the other parameters used for the simulation of all the models. Source: Galí (2015).

\subsection{Optimal policy}

The optimal monetary policy question discussed in this paper requires an evaluation of the household's utility as the criterion that the central bank maximizes subject to the economy's constraints. As a cornerstone of our analysis, the microfounded welfare loss measure

$$
\mathbb{W}=\frac{1}{2} \mathbb{E}_{0} \sum_{t=0}^{\infty} \beta^{t}\left(\pi_{t}^{2}+\frac{w_{x}}{w_{\pi}} x_{t}^{2}\right)
$$


where $w_{\pi}=\frac{\epsilon}{\Theta} \frac{\theta}{(1-\beta \theta)(1-\theta)}$ and $w_{x}=\gamma+\frac{\phi+\alpha}{1-\alpha}$ is derived from the second order approximation of the behavioral household's utility, as demonstrated in Appendix A.5.

\section{Commitment}

The central bank is assumed to be credible and able to commit to a policy plan that stabilizes the economy. It chooses a path for the output gap and inflation over the infinitely lived horizon to minimize a policy objective function, the welfare loss (Eq. 21).

\subsection{Analytical solution}

Solution 1 The central bank problem solution under commitment yields to the following FOCs

$$
\begin{gathered}
\pi_{t}+\varphi_{t}-\frac{M^{f}}{\beta} \varphi_{t-1}=0 \\
\frac{w_{x}}{w_{\pi}} x_{t}-\kappa \varphi_{t}=0
\end{gathered}
$$

where $\varphi_{t}$ is the Lagrange multiplier associated with the policy problem.

Proposition 1 A form of PLT is optimal when $\bar{m}=1$ and $m_{\pi}^{f}=1$, and a form of inflation targeting (IT) is optimal when this condition is not satisfied.

Proof. The Lagrangian of the central bank's problem is

$$
L_{t}=\mathbb{E}_{t} \sum_{t=0}^{\infty} \beta^{t}\left[\frac{1}{2}\left(\pi_{t}^{2}+\frac{w_{x}}{w_{\pi}} x_{t}^{2}\right)+\varphi_{t}\left(\pi_{t}-\kappa x_{t}-M^{f} \pi_{t+1}\right)\right]
$$

Deriving the Lagrangian with respect to $\pi_{t}$ yields the first FOC (Eq. 22). Deriving the latter with respect to $x_{t}$ yields the second FOC (Eq. 23). Consequently, we can write Eq. 22 in terms of the price level

$$
p_{t}+\varphi_{t}=p_{t-1}+\frac{M^{f}}{\beta} \varphi_{t-1}
$$

Two cases can be distinguished: (i) The case where the price level is stationary, i.e., $\frac{M^{f}}{\beta}=1$. Such a case prevails when $\bar{m}=1$ and $m_{\pi}^{f}=1$, and a form of PLT is optimal. (ii) Otherwise, a form of IT is optimal. 
Note that by combining Eq. 22 and Eq. 23 we obtain the following central bank targeting rule

$$
\pi_{t}=-\frac{w_{x}}{\kappa w_{\pi}}\left(x_{t}-\frac{M^{f}}{\beta} x_{t-1}\right)
$$

which has to be satisfied at every period to obtain optimal outcomes. Isolating the expression of the price level from Eq. 26 leads to

$$
p_{t}=-\frac{w_{x}}{\kappa w_{\pi}}\left(x_{t}+\left(1-\frac{M^{f}}{\beta}\right) \sum_{j=0}^{t-1} x_{j}\right)
$$

Applying the Proposition 1 to Eq. 27, and considering the case of optimal PLT where $\bar{m}=1$ and $m_{\pi}^{f}=1$, we end up with the following targeting rule

$$
p_{t}=-\frac{w_{x}}{\kappa w_{\pi}} x_{t}
$$

which satisfies the fact that the price level is stationary, as the output gap tends to be null in the long term. The PLT is an optimal outcome for monetary policymaking even in the presence of other forms of myopia such as interest rate, revenue, or output gap. The only requirement for this form of targeting to be optimal is the full attentiveness to inflation developments. Indeed, a central bank under this regime sets a target for the price level and adjusts its decisions accordingly. In case of a positive cost-push shock, for instance, price level jumps to a new level while the output gap opens up. To achieve its target, the central bank has to engineer a deflation. Consider the case where economic agents are myopic to inflation $\left(m_{\pi}^{f} \neq 1\right)$, the recessionary effect of monetary policy on output does not transmit completely to the price level ( through Eq. 27). Consequently, monetary policy has to engineer a second deflationary round to stabilize the price level, and so on until the target is achieved at the expense of depressing economic activity. Thus, for PLT to be socially optimal, a minimal condition of full attentiveness to inflation has to be satisfied even with the presence of the remaining forms of myopia.

In contrast, Gabaix (2019) concluded that PLT is not optimal with behavioral agents, but our result points that this conclusion is incomplete. The proposition derived in this section indicates the optimality of PLT in many behavioral cases. Referring to the cases described in 1, the cases of interest rate, output gap, and revenue myopia satisfy the proposition (Section 4.1), all exhibiting a form of PLT.

Under interest rate, output gap, and revenue myopia, people perfectly foresee inflation as there is no inflation myopia. Consequently, as the central bank (also) monitors perfect inflation expectations, it can implement PLT appropriately, which delivers the first best solution. 
In response to a cost-push shock, the central bank's commitment to engineering a deflation in the future has implications for the current inflation to the extent that behavioral agents-households and firms-are forward-looking in terms of this specific variable while myopic to other macroeconomic variables. The conclusion that bounded rationality implies suboptimality of PLT is shortsighted. Digging into different forms of bounded rationality shows that this targeting might be optimal in the cases highlighted earlier and that IT is optimal in the remaining cases.

The takeaway from this analysis is that, contrary to the existing monetary economics literature, there is no definitive answer in term of the optimal conduct of monetary policy. Depending on which myopia characterizing households and firms prevails, a central bank must choose the corresponding targeting.

\subsection{Simulation and welfare}

Fig. 1 presents the responses of the economy to a 1 percent cost-push shock. The cost-push shock implies a trade-off between the output gap and inflation. The intensity of such a trade-off differs slightly depending on the form of myopia.
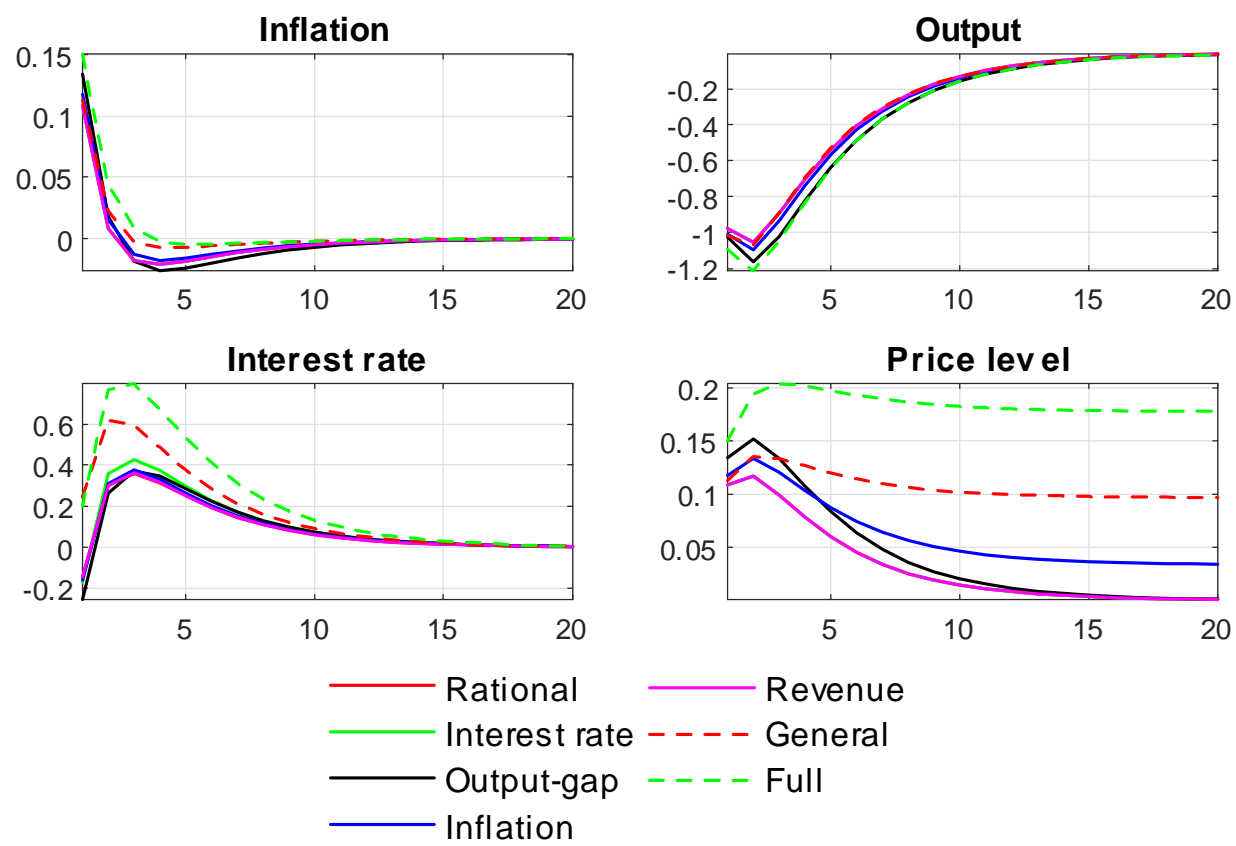

Figure 1: Impulse response functions of inflation, price level, output and interest rate following a $1 \%$ cost-push shock under commitment for each model.

For instance, full myopia entails a substantial increase in inflation with a significant drop in output. Such deviations require a strong reaction from the central bank. Furthermore, in this (full) myopia case, we notice that the price level never returns to its steady state after a cost-push shock, which corroborates the analytical result about the suboptimality of PLT in this particular case. 


\section{Discretion}

According to Plosser (2007), when the central bank is "not bound by previous actions or plans and thus is free to make an independent decision every period", monetary policy is called discretionary. In such a case, the central bank makes whatever decision is optimal in each period without committing itself to any future actions.

In this section, we characterize the second-best solutions of the central bank's optimization problem following a cost-push shock.

\subsection{Analytical solution}

In this regime, the central bank minimizes the welfare loss related to the decision period, taking into account that expectations are given, which yields to the following proposition.

Proposition 2 Discretionary central bank has to obey to the following targeting criterion when setting its optimal policy:

$$
\pi_{t}=-\frac{w_{x}}{\kappa w_{\pi}} x_{t}
$$

Proof. It is sufficient to write the Lagrangian and derive with respect to both endogenous variables to obtain FOCs. Once combined, we end up with the targeting rule for the central bank in this case.

After a cost-push shock, a discretionary central bank has to keep this proposition satisfied to minimize the welfare loss. When inflationary pressures arise, the policymaker has an incentive to drive output below its efficient level to accommodate the cost-push shock. While this proposition is silent about the influence of bounded rationality on a discretionary policy, the size of both output and inflation deviations due to the cost-push shock depends on myopia. To make this clear, we replace the Eq. 28 in the Phillips curve and solve forward, which yields the following expression for inflation

$$
\pi_{t}=\frac{\frac{w_{x}}{w_{\pi}}}{\frac{w_{x}}{w_{\pi}}+\kappa^{2}-\frac{w_{x}}{w_{\pi}} M^{f} \rho_{u}} u_{t}
$$

and by using the targeting rule Eq. 28, we obtain an expression for the output gap

$$
x_{t}=\frac{-\kappa}{\frac{w_{x}}{w_{\pi}}+\kappa^{2}-\frac{w_{x}}{w_{\pi}} M^{f} \rho_{u}} u_{t}
$$

These expressions state that the central bank has to let the output gap and inflation deviate proportionally to the cost-push shock $\left(u_{t}\right)$. Bounded rationality 
influences the magnitudes of these deviations through $\kappa$, which depends on output gap and inflation myopias, $m_{x}^{f}$ and $m_{\pi}^{f}$ respectively, and through $M^{f}$, which depends on the general and inflation myopia, $\bar{m}$ and $m_{\pi}^{f}$ respectively.

The optimal policy response entails an indeterminate price level but determinate inflation, which suggests a form of IT as the preferred regime for a central bank under discretion.

Although the type of myopia considered could impact the magnitudes of the reactions to a particular shock, bounded rationality under discretion does not impact the choice of the policy regime. The rationale under such a proposition is that, in this case, monetary policy takes expectations as exogenous and seek to only accommodate the shock in the current period. However, bounded rationality influences the expected reaction of macro variables to this shock, as highlighted in Eq. 29 and Eq. 30 and shown by the impulse response functions presented in the following section.

\subsection{Simulation and welfare}

A cost-push shock is assumed to understand the obtained optimal equilibrium (Eq. 29 and Eq. 30) by examining inflation and output gap reactions under different myopia scenarii. Fig. 2 presents the impulse response functions to a 1 percent cost-push shock under an optimal discretionary monetary policy.
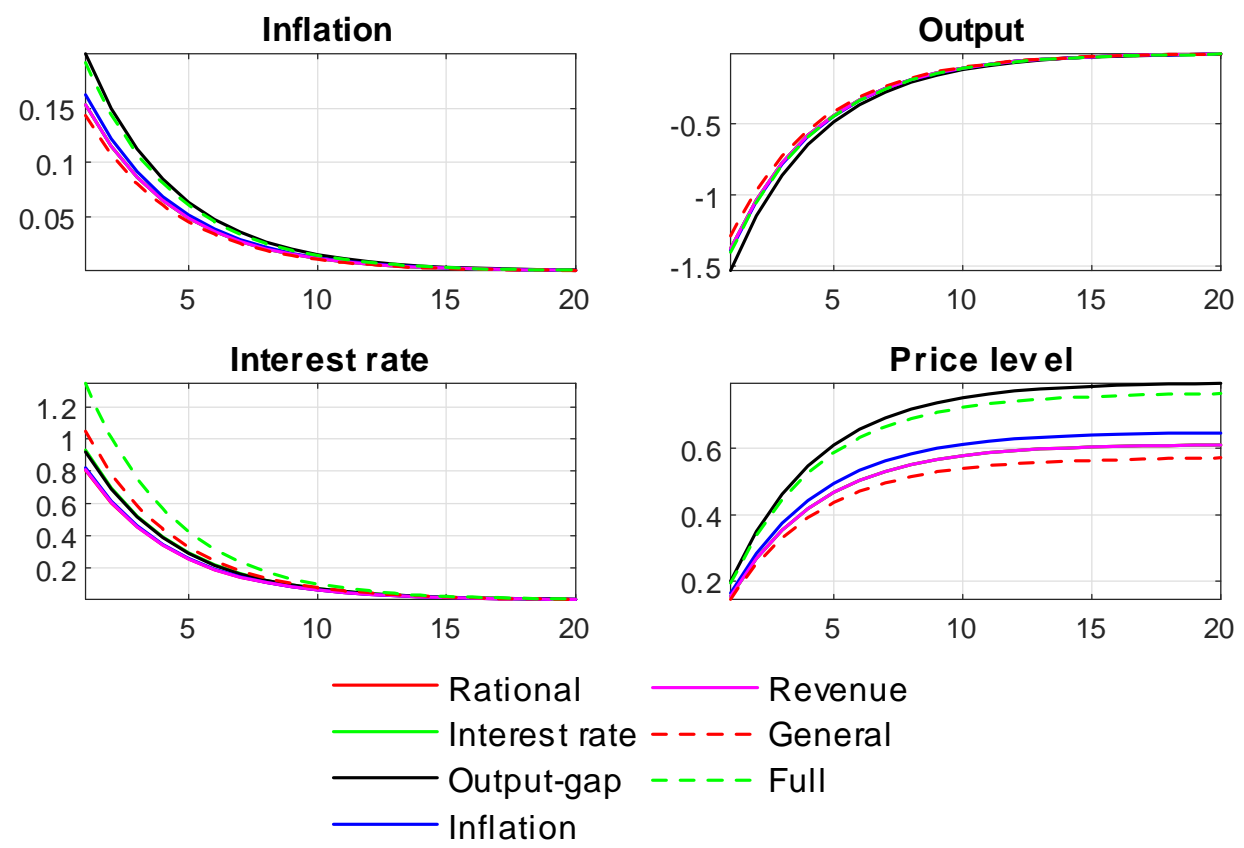

Figure 2: Impulse response functions of inflation, price level, output and interest rate following a $1 \%$ cost push shock under discretion for each model.

As discussed in Section 5.1, we can assess the deviation of both the output 
gap and inflation reacting to a cost-push shock. Differences arising in each type of myopia reflect the way myopia interacts with the proposed solution for inflation and the output gap (Eq. 29 and Eq. 30).

Two remarks are worth noting here. First, the optimal monetary policy reaction seeks to increase the policy rate to accommodate the inflation increase but aggressively compared to the rational benchmark-except for the case of revenue myopia. Second, as mentioned previously, the price level is not stationary in any case, which suggests an IT regime as the desirable monetary policy.

As reported in Table 4, the evaluation of welfare losses reveals that the optimal policy is better under general myopia than under the rational benchmark.

\begin{tabular}{|c|c|c|c|c|c|}
\hline No myopia & \multicolumn{5}{|c|}{ Myopia } \\
\hline & Interest rate & Inflation & Revenue & General & Full \\
\hline 0.270 & 0.386 & 0.287 & 0.270 & 0.236 & 0.341 \\
\hline
\end{tabular}

Table 4: Welfare losses under discretion.

Although this result could seem counterintuitive, one should remember that this form of myopia (general myopia) impacts the level of expectations of all macroeconomic variables or the model. In this case, people's expectations are distorted, which is consistent with a discretionary policymaker.

\section{Simple rules}

In this section, we determine the optimal coefficient values that minimize the central bank loss function of the various simple rules described in Table 5.

\begin{tabular}{|c|c|c|}
\hline Name & Targeting regime & Instrument-rule \\
\hline F1 & Flexible inflation & $i_{t}=\phi_{\pi} \pi_{t}+\phi_{y} \tilde{y}_{t}+\varepsilon_{t}^{m p}$ \\
\hline $\mathrm{F} 2$ & Flexible price level & $i_{t}=\phi_{p} p_{t}+\phi_{y} \tilde{y}_{t}+\varepsilon_{t}^{m p}$ \\
\hline F3 & Flexible NGDP growth & $i_{t}=\phi_{g}\left(\pi_{t}+\Delta \tilde{y}_{t}\right)+\phi_{y} \tilde{y}_{t}+\varepsilon_{t}^{m p}$ \\
\hline F4 & Flexible NGDP level & $i_{t}=\phi_{n}\left(p_{t}+\tilde{y}_{t}\right)+\phi_{y} \tilde{y}_{t}+\varepsilon_{t}^{m p}$ \\
\hline S1 & Strict inflation & $i_{t}=\phi_{\pi} \pi_{t}+\varepsilon_{t}^{m p}$ \\
\hline $\mathrm{S} 2$ & Strict price level & $i_{t}=\phi_{p} p_{t}+\varepsilon_{t}^{m p}$ \\
\hline S3 & Strict NGDP growth & $i_{t}=\phi_{g}\left(\pi_{t}+\Delta \tilde{y}_{t}\right)+\varepsilon_{t}^{m p}$ \\
\hline S4 & Strict NGDP level & $i_{t}=\phi_{n}\left(p_{t}+\tilde{y}_{t}\right)+\varepsilon_{t}^{m p}$ \\
\hline
\end{tabular}

Table 5: Regime names, descriptions and simple rules

The instrument rules described in Table 5 reproduce the central bank's instrument rules when reacting only to the targeted variable, in a strict targeting sense (rules S1 to S4), and when reacting to real fluctuations in addition to its primary target, in a flexible sense (rules F1 to F4). Note that, in some cases, the central 
bank does not restrict its attention only to endogenous variables, which is why the monetary policy shock $\left(\varepsilon_{t}^{m p}\right)$ is added to reflect the deviations of the central bank from its rule.

Hereafter, we provide the optimal coefficient values (Section 6.1) and welfare losses (Section 6.2).

\subsection{Optimal coefficient values}

Table 6 reports the optimal values ${ }^{19}$ of $\phi_{\pi}$, the weight on inflation; $\phi_{y}$, the weight on the output gap; $\phi_{p}$, the weight on the price level; $\phi_{g}$ the weight on NGDP growth; and $\phi_{n}$ the weight on the NGDP level for different monetary policy rules.

\begin{tabular}{lcccccccccccc} 
& \multicolumn{2}{c}{ F1 } & \multicolumn{2}{c}{ F2 } & \multicolumn{2}{c}{ F3 } & \multicolumn{2}{c}{ F4 } & S1 & S2 & S3 & S4 \\
& $\phi_{\pi}$ & $\phi_{y}$ & $\phi_{p}$ & $\phi_{y}$ & $\phi_{g}$ & $\phi_{y}$ & $\phi_{n}$ & $\phi_{y}$ & $\phi_{\pi}$ & $\phi_{p}$ & $\phi_{g}$ & $\phi_{n}$ \\
No (rational) & 1.96 & 0.25 & 0.33 & 0.0 & 2.62 & 0.5 & 0.17 & 0.0 & 2.37 & 0.34 & 3.90 & 0.17 \\
Interest rate & 2.44 & 0.20 & 0.39 & 0.0 & 3.32 & 0.5 & 0.20 & 0.0 & 3.11 & 0.40 & 4.00 & 0.20 \\
Output gap & 1.39 & 0.32 & 0.26 & 0.0 & 1.81 & 0.5 & 0.13 & 0.0 & 2.02 & 0.27 & 3.43 & 0.13 \\
Inflation & 1.43 & 0.27 & 0.30 & 0.0 & 1.55 & 0.5 & 0.15 & 0.0 & 1.99 & 0.31 & 3.26 & 0.15 \\
Revenue & 2.03 & 0.21 & 0.33 & 0.0 & 2.63 & 0.5 & 0.17 & 0.0 & 2.37 & 0.34 & 3.91 & 0.17 \\
General & 2.05 & 0.14 & 0.56 & 0.0 & 1.61 & 0.5 & 0.25 & 0.0 & 2.38 & 0.58 & 3.34 & 0.25 \\
Full & 1.54 & 0.18 & 0.49 & 0.0 & 1.10 & 0.5 & 0.21 & 0.0 & 2.10 & 0.50 & 2.82 & 0.21
\end{tabular}

Table 6: Coefficients of the optimal simple rules (F1 to S4) under different myopia.

As shown in Table 6, the inflation coefficients under the flexible and strict IT regimes (F1 and $\mathrm{S} 1$ ) are strictly greater than one in all myopia cases, which is in line with the stability condition (Galí, 2008, 2015). As the results show, myopia does impact the coefficients of the optimal simple rules. Consequently, people's perceptions of future macroeconomic dynamics lead the central bank to react differently under each regime for each myopia.

Compared to the rational case, interest rate myopia appears to increase the sensitivity of the policy instrument to the central bank target. Monetary policy is transmitted to the output gap and inflation through the IS and Phillips Curve equations, conditional on the model coefficients influenced by behavioral myopia parameters. Agents' myopia to the future interest rate weakens the transmission of monetary policy to the output gap. To control its target, the central bank has to react aggressively in order to send the appropriate signal. Intuitively, the policymaker needs to strongly signal its control over its target when people misperceive the interest rate for each targeting case.

For all considered rules, the output gap myopia decreases the sensitivity of the interest rate to the central bank's target compared to the rational case. However,

\footnotetext{
${ }^{19}$ Optimizations are based on the calibration presented in Section 3.2.
} 
the reaction to the output gap becomes stronger compared to the rational case in the flexible IT rule. The reason for this shift is related to the fact the output gap myopia implies that the transmission from the output gap to inflation becomes weak, while the other channel from the interest rate to output gap remains unaffected by this myopia. For instance, to have the desired impact on inflation, the central bank reacts strongly to the output gap but softly to inflation in F1. By misperceiving the output gap dynamics, this economy lacks the pass-through from the output gap to the nominal variables, which are the targeted variables for the central bank. Then, the central bank reaction function is less sensitive to its nominal target compared to the rational case.

Regarding inflation myopia, the sensitivity to targeted variables is smaller than the rational case due to the higher transmission from inflation expectations and the output gap to inflation. The case for revenue myopia is quite similar, given that this myopia increases the feedback from output gap expectations and the interest rate to the output gap, which feeds to inflation, while the transmission from the output gap to inflation remains constant. That is why we see such similar coefficients in reaction to the targeted variable compared to the rational case.

The central bank should react aggressively to curb expectations and impact the desired variables under general and full myopia.

Another set of results is derived when comparing the considered targeting regimes. The characteristics of the optimal rules differ in their sensitivity to different myopia cases. The central bank appears to be more sensitive to its target when operating under strict targeting compared to flexible targeting.

The nominal income coefficients associated with strict NGDP growth targeting (S3) are higher than the flexible NGDP growth targeting coefficients (F3) across all types of myopia, a result in line with the literature (Rudebusch, 2002; Benchimol and Fourçans, 2019). As these coefficients are also larger than one, they respect the necessary stability conditions (Taylor principle). Table 6 reveals that when the central bank targets the NGDP level (F4 and S4) or the price level (F2 and S2), both in the strict and flexible senses, the coefficients are positive but lower than one, a result in line with Rudebusch (2002).

If we compare PLT in flexible and strict senses, we find similar results. The same result is found when comparing NGDP level targeting in flexible and strict forms. When the central bank targets a form of price level or NGDP objective, the output gap objective becomes not desirable. This result consists of a divine coincidence between stabilizing the price level and the output gap. Indeed, a form of PLT leads to self-stabilizing dynamics for the output gap. If the price level deviation from its target increases, say a decrease (increase) from its target, the central bank 
takes correcting measures to increase (decrease) inflation in the future to restore the targeted price level, inducing a lower real interest rate that contributes to boosting the output gap.

All the optimal coefficients depend more or less on agent myopia, and it is clear that interest rate myopia delivers the most substantial amplitude compared to other types of myopia under IT and NGDP growth targeting. Under price level and NGDP level targeting regimes, it is general myopia that delivers the highest coefficients.

For the optimal values of $\phi_{p}$ in rules F2 and S2, regardless of whether the central bank targets the price level flexibly or strictly, the sensitivity of the policymaker's instrument to the price level does not vary significantly between the flexible and strict regimes. This is also the case between rules F4 and S4.

The coefficient of the output gap varies across the different types of myopia and rules considered. First, the rules reflecting flexible PLT (F2) and NGDP level targeting (F4) show null optimal values for the output gap, which suggests that the central bank does not have to care about real fluctuations under these regimes. Second, the coefficient on the output gap in the flexible IT rule (F1) displays a slight sensitivity to myopia.

\subsection{Which rule best describes the first best solution?}

The performance of policy rules is compared using the same microfounded welfare criterion as in Section 5 and Section 4. The welfare losses for each rule are reported in Table 3.

Flexible targeting rules do not necessarily induce welfare losses compared to strict rules. Most flexible targeting rules generate similar welfare losses compared to their corresponding strict targeting rules. For instance, welfare losses are identical between F1 and S1.

Strict PLT delivers the lowest welfare among the considered rules. Note that the welfare losses associated with this rule are similar to the flexible PLT rule through different myopia cases. The reason behind this equivalence lies in the optimal value of the output gap feedback to the interest rate in rule F2, which is null, a case for a divine coincidence when the central bank is pursuing a price level objective.

Moreover, the rational case delivers similar welfare losses to interest rate and revenue myopia cases as in the previous results (Tables 3 and 4).

Regarding other bounded rationality cases, it is clear that across those targeting rules, output gap and full myopia imply the most important welfare losses compared to the other cases. However, general myopia, combined with appropriate central bank action, sometimes yields to smaller welfare losses compared to the rational 


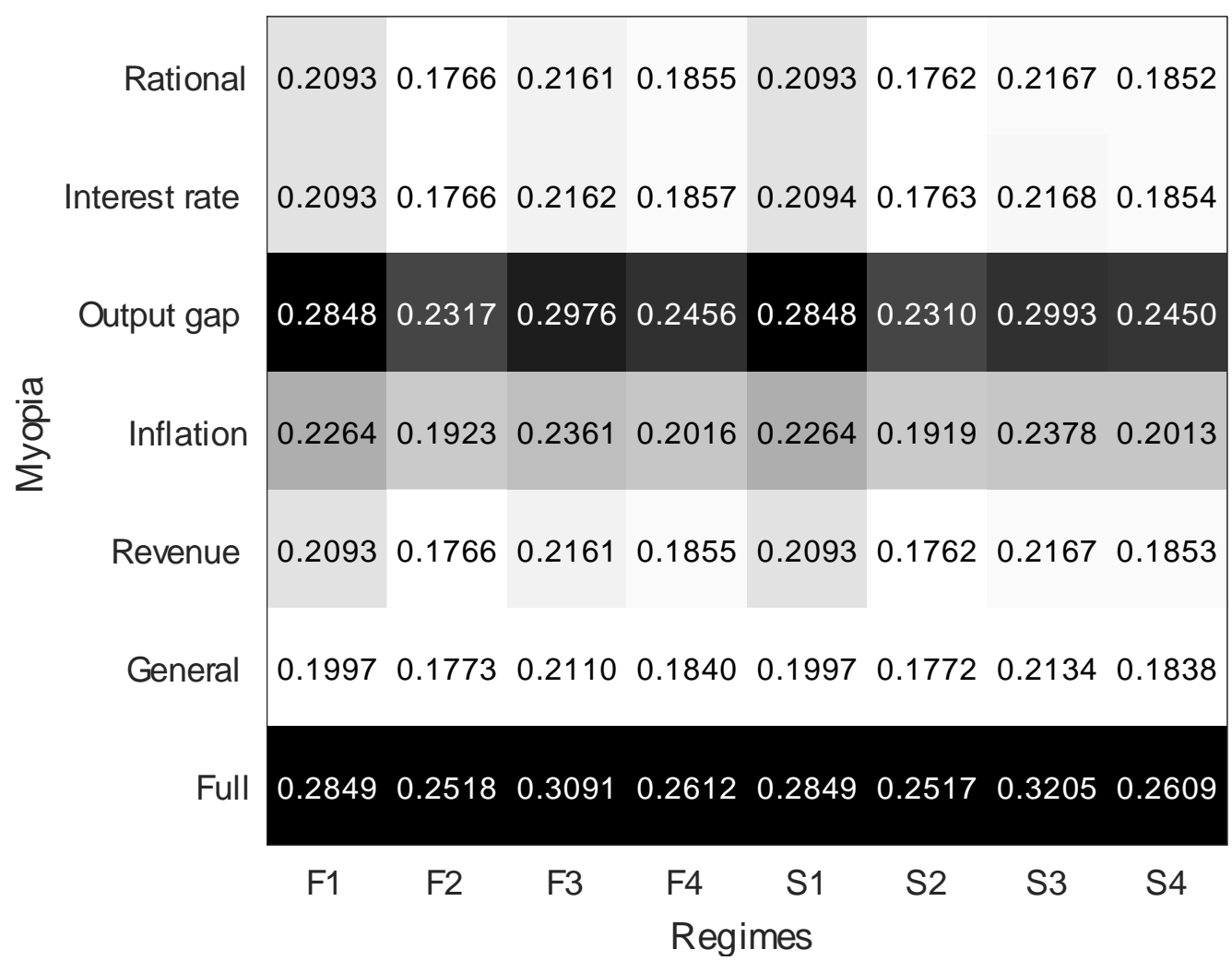

Figure 3: Welfare losses under optimal simple rules. Note: the shading scheme is defined separately in relation to each column. The lighter the shading is, the smaller the welfare loss.

case as in the discretion case (Table 4).

As the welfare analysis shows (Table 3), the best monetary policy rule (that delivers the lowest welfare loss) is the strict PLT rule, whatever type of myopia considered. While this result is interesting, it demonstrates the inability of these simple rules to replicate the first best solution under commitment, which emphasizes that the optimal policy depends on the type of myopia characterizing agents.

\section{Discussion}

Analyzing optimal monetary policy through the lens of a behavioral perspective leads to a richer set of results. Some results corroborate the findings in the rational expectations literature about optimal monetary policy-as in section 4 when setting myopia parameters to 1 . Other results contrast with the views of the behavioral macroeconomic literature-when myopia parameters are different from 1. Our results shed light on an old debate about the inability of simple rules to constitute a guideline for monetary policy.

Relaxing the rational agent hypothesis contributes, in the case of commitment, to addressing one of the critiques of the New Keynesian model, namely, the persis- 
tence of macroeconomic variables with respect to monetary policy shocks (Walsh, 2017; Fuhrer and Moore, 1995). We come to the same conclusion as Woodford (2010), in which near-rational expectations are used, about the history dependence of the targeting rule under commitment. One can infer that assuming more realistic agents in the New Keynesian model would provide a more accurate replication of the impact of monetary policy.

Our result on the optimality of a form of PLT in the cases of interest rate, output gap or revenue myopia and the optimality of a form of IT in the remaining cases departs from the existing monetary economics literature but also from Gabaix (2019). Bounded rationality gives reason to both sides, the proponent of PLT and those in favor of IT, by setting the borders between the appropriate use of each targeting regime depending on the agents' myopia. While this departure from rationality complicates expectation management, it offers a rich set of policy regimes-IT and PLT-for the policymaker to choose given the state of the world-myopia.

The baseline rational New Keynesian framework recommends a form of PLT as the optimal policy (Galí and Gertler, 1999; Woodford, 2003). This recommendation is nested in our results by shutting down myopia parameters (in section 4). Deviations from this benchmark like in the rational inattention framework (Maćkowiak and Wiederholt, 2009, 2015) find small differences in terms of welfare compared to the rational case, which does not alter the policy conclusions of the rational expectations model.

Learning models, as surveyed in Eusepi and Preston (2018), conclude that a form of PLT could be a proxy for the optimal policy.

By deviating from the rational agent hypothesis and using price setters' information stickiness, Ball et al. (2005) find that flexible PLT is optimal. Honkapohja and Mitra (2018) employs a nonlinear New Keynesian model under learning to show that PLT performs well depending on the credibility of the central bank. Using different deviations from rationality, namely bounded rationality, supports the finding of PLT optimality. Gabaix (2019) completely dismisses the latter result and concludes that PLT is suboptimal.

By exploring all possible forms of bounded rationality, we emphasize the optimality of PLT in some cases, as the existing literature does, while validating the results of Gabaix (2019) only under some specific bounded rationality configurations. In light of the real experiment led by Amano et al. (2011), who finds that PLT is better suited to real agents' beliefs, which are presumably boundedly rational, we cannot ignore that PLT is the prescribed monetary policy.

Robustness analysis (Appendix B) shows that our results are robust to the model's calibration of the structural parameters. It also shows that high general 
myopia always improves welfare losses under commitment, discretion, and optimal simple rule regimes. Indeed, bounded rationality is not necessarily associated with decreased welfare. Extreme general myopia can increase welfare whatever the monetary policy regime.

Regarding our result under commitment, one could expect that optimal simple rules would allow us to replicate the first best solution emphasizing IT in some cases (small welfare losses) and PLT in the remaining cases. However, under these instrument rules, the welfare loss evaluation points to the desirability of strict PLT as a proxy for the optimal monetary policy, regardless of the bounded rationality type. Such a result is in sharp contrast with the policy prescription under commitment.

This result recalls the old debate regarding the instrument rules versus targeting rules, as emphasized in Svensson (2003). Mechanical instrument rules, as a guideline for monetary policy, are likely to be inadequate for optimizing and forward-looking central banks. Svensson (2003) argues that the concept of targeting rules is more appropriate to the forward-looking nature of monetary policy. In the same vein, the inability of simple rules to replicate the commitment solution is a clear case of the shortcomings related to this kind of monetary policy conception. Managing expectations in a behavioral world needs to deviate from a mechanical rule and enlarge the scope to a targeting rule that provides more room for switching policies as people's perceptions change.

\section{$8 \quad$ Policy implications}

Following the Global Financial Crisis, central bank and policy institution members called for an in-depth revision of the IT framework, which shaped the policy decisions of major central banks over several decades (Bernanke, 2017; Blanchard and Summers, 2019; Evans, 2018). Some policymakers advocate the appropriateness of PLT as a measure to overcome the challenges brought by the Zero Lower Bound (Bernanke, 2017). Others want to retain the current IT framework and make some adjustment to its parameters, such as raising the inflation target (Blanchard and Summers, 2019) or allowing interest rates to be negative. Even before the crisis, the debate between IT and PLT was an old debate of the modern monetary policy era (Svensson, 1999).

Our result bridges the gap between these two competing views about which kind of monetary policy targeting is optimal. Both forms of targeting, namely PLT and IT, could be optimal but in different circumstances. Our findings show that assessing bounded rationality is a crucial indicator for the central bank to decide whether it has to pursue an IT or PLT. 
The evaluation of the instrument rules indicates the desirability of strict PLT over the other monetary policy targeting regimes, which is in line with the literature surveyed by Hatcher and Minford (2016) in the rational case. However, regarding the bounded rationality cases, this homogeneity of the choice of the targeting rule leaves us with much concern about the inability of these simple instrument rules to replicate the optimal policy as a first best. This result questions the usefulness of these rules for stabilizing the economy while taking into account bounded rationality as an essential policymaking ingredient.

The inability of simple rules to replicate the first best solution calls for a reconsideration of their roles in the conduct of monetary policy. Furthermore, their mechanical nature is not adapted to the changing nature of inattention that agents experience in different circumstances. We join Svensson (2003) in calling for including targeting rules (as derived in Proposition 1) to the central banking apparatus in setting monetary policy decisions.

Overall, agents' expectations matter for monetary policy conduct. A concrete illustration is policymakers' desire to educate the public through intensive communication. Central banks have, for several decades, educated agents in economics to increase public understanding and trust of their monetary policies, among other objectives. Such a program may be perceived as an effort to attenuate myopia, thus guiding agents to rationality. Even if bounded rationality is not a curable disease-although not always a disease, as myopia sometimes improves welfare-and is inherent to human functioning, it should motivate central banks to act using the correct tools by taking into account agents' myopia to improve welfare. Convincing central bank staffs to explore, monitor and analyze agents' myopia constitutes a relevant policy recommendation of this paper. Assessing the degree to which economic agents are myopic is one of the areas that central banks should invest in more. Borrowing an analogy from Thaler (2016), the central bank should invest in studying the degree to which Homo sapiens are myopic and act consistently rather than educate people and attempt to transform humans into Homo economicus.

\section{Conclusion}

Optimal monetary policy is assessed in a behavioral New Keynesian framework to show that the first best solution depends on the type of myopia characterizing agents. While a form of PLT is optimal in some myopia cases, IT is more appropriate in the remaining cases.

No definitive answer about the targeting policy to adopt in a behavioral setting can be drawn. Neither IT nor PLT is consistently optimal under all states of the 
world.

Bounded rationality matters for the conduct of monetary policy. In an attempt to implement the commitment result through an instrument rule, we find that optimal simple rules favor strict PLT in all bounded rationality cases we consider. Such a result leaves us with a puzzling observation about the replication of the first best solution.

The inability of simple rules to replicate the first best solution calls for a reconsideration of their roles in the conduct of monetary policy. This finding opens a new reflection about the instrument rules in an economy with behavioral agents. While these types of rules provide policymakers with a simple monetary policy tool, it is not clear what role these rules could play in a behavioral world. Bounded rationality is not necessarily associated with decreased welfare. Several forms of economic inattention, especially extreme ones, can increase welfare. By contrast, output gap myopia implies significant welfare losses compared to the rational case. The central bank has to assess and monitor different types of myopia to optimally conduct monetary policy.

\section{References}

Akerlof, G. A., Yellen, J. L., 1987. Rational models of irrational behavior. American Economic Review 77 (2), 137-142.

Amano, R., Engle-Warnick, J., Shukayev, M., 2011. Price-level targeting and inflation expectations: experimental evidence. Tech. rep., Bank of Canada.

Andrade, P., Le Bihan, H., 2013. Inattentive professional forecasters. Journal of Monetary Economics 60 (8), 967-982.

Bachmann, R., Berg, T. O., Sims, E. R., 2015. Inflation expectations and readiness to spend: cross-sectional evidence. American Economic Journal: Economic Policy $7(1), 1-35$.

Ball, L., Mankiw, N. G., Reis, R., 2005. Monetary policy for inattentive economies. Journal of Monetary Economics 52 (4), 703-725.

Benchimol, J., Fourçans, A., 2019. Central bank losses and monetary policy rules: a DSGE investigation. International Review of Economics and Finance 61 (1), 289-303.

Bernanke, B. S., 2017. Monetary policy in a new era. In: Prepared for conference 
titled "Rethinking Macroeconomic Policy", Peterson Institute for International Economics, Washington DC, October. pp. 1-49.

Blanchard, O. J., 2009. The state of macro. Annual Review of Economics 1 (1), 209-228.

Blanchard, O. J., 2018. On the future of macroeconomic models. Oxford Review of Economic Policy 34 (1-2), 43-54.

Blanchard, O. J., Summers, L. H., 2019. Evolution or Revolution? Rethinking Macroeconomic Policy after the Great Recession. Cambridge, MA: MIT Press.

Calvo, G., 1983. Staggered prices in a utility-maximizing framework. Journal of Monetary Economics 12 (3), 383-398.

Clarida, R., Galí, J., Gertler, M., 1999. The science of monetary policy: a New Keynesian perspective. Journal of Economic Literature 37 (4), 1661-1707.

Coibion, O., Gorodnichenko, Y., 2015. Information rigidity and the expectations formation process: a simple framework and new facts. American Economic Review 105 (8), 2644-2678.

De Grauwe, P., 2012. Lectures on behavioral macroeconomics. No. 9891 in Economics Books. Princeton, NJ: Princeton University Press.

Eusepi, S., Preston, B., 2018. The science of monetary policy: an imperfect knowledge perspective. Journal of Economic Literature 56 (1), 3-59.

Evans, C. L., 2018. Some practical considerations for monetary policy frameworks. Speech at the Shadow Open Market Committee meeting, Manhattan Institute, New York City.

Evans, G. W., Honkapohja, S., 2012. Learning and expectations in macroeconomics. Princeton, NJ: Princeton University Press.

Evans, G. W., Honkapohja, S., 2013. Learning as a rational foundation for macroeconomics and finance. In: Frydman, R., Phelps, E. S. (Eds.), Rethinking Expectations: The Way Forward for Macroeconomics. Princeton University Press, Ch. 2, pp. 68-111.

Fuhrer, J. C., Moore, G., 1995. Inflation persistence. Quarterly Journal of Economics 110 (1), 127-159.

Gabaix, X., 2014. A sparsity-based model of bounded rationality. Quarterly Journal of Economics 129 (4), 1661-1710. 
Gabaix, X., 2019. A behavioral New Keynesian model. Mimeo, Harvard University.

Galí, J., 2008. Monetary policy, inflation and the business cycle: an introduction to the New Keynesian framework, 1st Edition. Princeton, NJ: Princeton University Press.

Galí, J., 2015. Monetary policy, inflation and the business cycle: an introduction to the New Keynesian framework, 2nd Edition. Princeton, NJ: Princeton University Press.

Galí, J., Gertler, M., 1999. Inflation dynamics: a structural econometric analysis. Journal of Monetary Economics 44 (2), 195-222.

Gennaioli, N., Ma, Y., Shleifer, A., 2016. Expectations and investment. NBER Macroeconomics Annual 30 (1), 379-431.

Hatcher, M., Minford, P., 2016. Stabilisation policy, rational expectations and pricelevel versus inflation targeting: a survey. Journal of Economic Surveys 30 (2), $327-355$.

Honkapohja, S., Mitra, K., 2018. Price level targeting with evolving credibility. Research Discussion Papers 5/2018, Bank of Finland.

Kahneman, D., 1973. Attention and effort. Vol. 1063. Englewood Cliffs, NJ: Prentice-Hall.

Maćkowiak, B., Wiederholt, M., 2009. Optimal sticky prices under rational inattention. American Economic Review 99 (3), 769-803.

Maćkowiak, B., Wiederholt, M., 2015. Business cycle dynamics under rational inattention. Review of Economic Studies 82 (4), 1502-1532.

Modigliani, F., Cohn, R. A., 1979. Inflation, rational valuation and the market. Financial Analysts Journal 35 (2), 24-44.

Oates, W., 1991. On the nature and measurement of fiscal illusion: a survey. In: Oates, W. (Ed.), Studies in Fiscal Federalism. Brookfield, VT: Edward Elgar, pp. 431-448.

Plosser, C. I., 2007. Credibility and commitment: a speech presented to the New York Association for Business Economics, March 6, 2007, and as the Hutchinson Lecture, University of Delaware, April 10, 2007. Speech 4, Federal Reserve Bank of Philadelphia. 
Rudebusch, G., 2002. Assessing nominal income rules for monetary policy with model and data uncertainty. Economic Journal 112 (479), 402-432.

Sims, C. A., 2003. Implications of rational inattention. Journal of Monetary Economics 50 (3), 665-690.

Stiglitz, J. E., 2011. Rethinking macroeconomics: what failed, and how to repair it. Journal of the European Economic Association 9 (4), 591-645.

Svensson, L. E. O., 1999. Price-level targeting versus inflation targeting: a free lunch? Journal of Money, Credit and Banking 31 (3), 277-295.

Svensson, L. E. O., 2003. What is wrong with Taylor rules? Using judgment in monetary policy through targeting rules. Journal of Economic Literature 41 (2), 426-477.

Taylor, J. B., 1993. Discretion versus policy rules in practice. Carnegie-Rochester Conference Series on Public Policy 39 (1), 195-214.

Thaler, R. H., 2016. Behavioral economics: past, present, and future. American Economic Review 106 (7), 1577-1600.

Wagner, R. E., 1976. Revenue structure, fiscal illusion, and budgetary choice. Public Choice 25 (1), 45-61.

Walsh, C., 2017. Monetary theory and policy. Cambridge, MA: MIT Press.

Woodford, M., 2003. Interest and prices: foundations of a theory of monetary policy. Princeton, NJ: Princeton University Press.

Woodford, M., 2010. Robustly optimal monetary policy with near-rational expectations. American Economic Review 100 (1), 274-303.

Woodford, M., 2013. Macroeconomic analysis without the rational expectations hypothesis. Annual Review of Economics 5 (1), 303-346.

\section{Appendix}

\section{A Derivations}

\section{A.1 IS curve}

In this section, we use the Feynman-Kac methodology to derive the Taylor expansion of the consumption deviations. 
The Lagrangian of the optimization problem is

$$
L=\sum_{t=0}^{\infty} \beta^{t} u\left(c_{t}, N_{t}\right)+\sum_{t=0}^{\infty} \beta^{t} \lambda_{t}^{k}\left(k_{t}-\left(1+r_{t}\right)\left(k_{t-1}-c_{t-1}+y_{t-1}\right)\right)
$$

where $r_{t}=\bar{r}+m_{r} \hat{r}_{t}, y_{t}=\bar{y}+m_{y} \hat{y}_{t}$, and $\lambda_{t}$ is the Lagrange multiplier, which is equal to $\partial V\left(k_{t}\right) / \partial k_{t}$, the derivative of the value function with respect to $k$.

The value function is defined $\operatorname{as}^{20} V\left(k_{t}\right)=\max _{c}\left\{u(c)+\beta V\left(k_{t+1}\right)\right\}$

At the optimum, the agent solves the following problem: $V(k)=\max _{c, k}\{L\}$. The envelope theorem implies that

$$
\frac{\partial V}{\partial r_{t}}=\frac{\partial L}{\partial r_{t}}=\beta^{t}\left[\frac{\partial u\left(c_{t}\right)}{\partial r_{t}}+\beta \lambda_{t}^{k}\left(k_{t}-c_{t}+y_{t}\right)\right]
$$

By deriving this expression with respect to $k_{0}$, we find that

$$
\frac{\partial}{\partial k_{0}}\left(\frac{\partial V}{\partial r_{t}}\right)=\beta^{t} \frac{\partial k_{t}}{\partial k_{0}} \frac{\partial}{\partial k_{t}}\left[\frac{\partial u\left(c_{t}\right)}{\partial r_{t}}+\beta \lambda_{t}^{k}\left(k_{t}-c_{t}+y_{t}\right)\right]
$$

By applying this formula to the problem at hand and taking into account the derivative of the value function in the default case, $\lambda_{t}^{k}=\frac{\partial V}{\partial k_{t}}=\left(\bar{y}+\frac{r}{R} \frac{\phi}{\phi+\gamma} k\right)^{-\gamma}$, we obtain

$$
V_{r, k}=\beta^{t} \frac{\partial}{\partial k_{t}}\left[\beta\left(\frac{\bar{r}}{R} \frac{\phi}{\phi+\gamma} k_{t}+\bar{y}\right)^{-\gamma} \frac{k_{t}}{R}\right]
$$

where $V_{r, k}=\frac{\partial}{\partial k_{0}}\left(\frac{\partial V}{\partial r_{t}}\right)$.

By deriving and simplifying the expression above, we obtain

$$
V_{r, k}=\frac{1}{R^{t+2}} c_{0}^{-\gamma-1}\left(-\gamma \frac{\bar{r}}{R} \frac{\phi}{\phi+\gamma} k_{0}+c_{0}\right)
$$

Since $u_{c_{0}}=V_{k_{0}}$, we have $u_{c c} \partial_{\hat{r}} c_{0}=\partial_{\hat{r}} V_{k_{0}}$, which implies

$$
\partial_{\hat{r}} c_{0}=\frac{\partial_{\hat{r}}\left(\frac{\partial V}{\partial k_{t}}\right)}{u_{c c}}=\frac{1}{R^{t+2}}\left(\frac{\bar{r}}{R} \frac{\phi}{\phi+\gamma} k_{0}-\frac{1}{\gamma} c_{0}\right)
$$

which gives the expression for $b_{r}\left(k_{t}\right)=\frac{1}{R^{t+2}}\left(\frac{\bar{r}}{R} \frac{\phi}{\phi+\gamma} k_{0}-\frac{1}{\gamma} c_{0}\right)$.

We take the derivative of the value function with respect to $y_{t}$. Applying the

\footnotetext{
${ }^{20}$ In this section, because FOCs with respect to consumption are considered, the labor supply $\left(N_{t}\right)$ is omitted.
} 
envelope theorem yields

$$
\frac{\partial V}{\partial y_{t}}=\frac{\partial L}{\partial y_{t}}=\beta^{t}\left(\frac{\partial u\left(c_{t}\right)}{\partial y_{t}}+\beta \lambda_{t}^{k}\left(1+r_{t}\right)\right)
$$

By deriving this expression with respect to $k_{0}$, we find the following expression:

$$
\frac{\partial}{\partial k_{0}}\left(\frac{\partial V}{\partial y_{t}}\right)=\beta^{t} \frac{\partial k_{t}}{\partial k_{0}} \frac{\partial}{\partial k_{t}}\left[\frac{\partial u\left(c_{t}\right)}{\partial y_{t}}+\beta \lambda_{t}^{k}\left(1+r_{t}\right)\right]
$$

Eq. 38 can be simplified as

$$
\frac{\partial}{\partial k_{0}}\left(\frac{\partial V}{\partial y_{t}}\right)=\frac{1}{R^{t}}\left(-\gamma \frac{\bar{r}}{R} c_{0}^{-\gamma-1}\right)
$$

Since $u_{c_{0}}=V_{k_{0}}$, we have $u_{c c} \partial_{\hat{y}} c_{0}=\partial_{\hat{y}} V_{k_{0}}$, which implies

$$
\partial_{\hat{y}} c_{0}=\frac{\partial_{\hat{y}}\left(\frac{\partial V}{\partial k_{0}}\right)}{u_{c c}}=\frac{\bar{r}}{R^{t+1}}
$$

Once we obtain Eqs. 36 and 40, the Taylor expansion of $\hat{c}$ can be expressed as

$$
\hat{c}_{t}=\mathbb{E}_{t} \sum_{\tau \geq t} \frac{b_{r \mid k=0} \hat{r}_{\tau}+b_{y} \hat{y}_{\tau}}{R^{\tau-t+1}}
$$

where $b_{r}=\frac{1}{R}\left(\frac{\bar{r}}{R} k_{0}-\frac{1}{\gamma} c_{0}\right)$ and $b_{y}=\bar{r}$.

For the behavioral agent expression, 41 becomes

$$
\hat{c}_{t}=\mathbb{E}_{t}^{B R} \sum_{\tau \geq t} \frac{b_{r \mid k=0} \hat{r}_{\tau}+b_{y} \hat{y}_{\tau}}{R^{\tau-t+1}}
$$

Recall from Gabaix (2019) the term structure of attention: $\mathbb{E}_{t}^{B R}\left[\hat{r}_{t+k}\right]=m_{r} \bar{m}^{k} \mathbb{E}_{t}\left[\hat{r}_{t+k}\right]$ and $\mathbb{E}_{t}^{B R}\left[\hat{y}_{t+k}\right]=m_{y} \bar{m}^{k} \mathbb{E}_{t}\left[\hat{y}_{t+k}\right]$, where $\bar{m}, m_{r}$ and $m_{y}$ are general, interest rate and revenue myopia, respectively. By replacing those expressions in Eq. 42, we obtain

$$
\hat{c}_{t}=\mathbb{E}_{t} \sum_{\tau \geq t} \frac{\bar{m}^{\tau-t}}{R^{\tau-t+1}}\left(b_{r \mid k=0} m_{r} \hat{r}_{\tau}+b_{y} m_{y} \hat{y}_{\tau}\right)
$$

Dividing Eq. 43 by $\bar{c}$, we find

$$
\frac{\hat{c}_{t}}{\bar{c}}=\mathbb{E}_{t} \sum_{\tau \geq t} \frac{\bar{m}^{\tau-t}}{R^{\tau-t+1}}\left(\frac{b_{r \mid k=0}}{\bar{c}} m_{r} \hat{r}_{\tau}+b_{y} m_{y} \frac{\hat{y}_{\tau}}{\bar{c}}\right)
$$

The market clearing condition is $y_{t}=c_{t}$, and thus $\frac{\hat{c}_{t}}{\bar{c}}=\frac{\hat{y}_{\tau}}{\bar{c}}=\tilde{y}_{t}$ is the output 
gap. Moreover, $\frac{b_{r \mid k=0}}{\bar{c}}=\frac{1}{\bar{c}} \frac{1}{R}\left(-\frac{1}{\gamma} c_{0}\right)=-\frac{1}{\gamma R}$.

Then, Eq. 44 becomes

$$
\tilde{y}_{t}=\mathbb{E}_{t} \sum_{\tau \geq t} \frac{\bar{m}^{\tau-t}}{R^{\tau-t+1}}\left(-\frac{1}{\gamma R} m_{r} \hat{r}_{\tau}+\bar{r} m_{y} \tilde{y}_{\tau}\right)
$$

Expanding this expression yields

$$
\tilde{y}_{t}=-\frac{1}{\gamma R^{2}} m_{r} \hat{r}_{t}+\frac{\bar{r}}{R} m_{y} \tilde{y}_{t}+\frac{\bar{m}}{R} \mathbb{E}_{t} \tilde{y}_{t+1}
$$

which can be simplified to

$$
\tilde{y}_{t}=M \mathbb{E}_{t}\left[\tilde{y}_{t+1}\right]-\sigma \hat{r}_{t}
$$

where $M=\frac{\bar{m}}{R-\bar{r} m_{y}}, \sigma=\frac{m_{r}}{\gamma R\left(R-r m_{y}\right)}$ and $R=1 / \beta$.

\section{A.2 Phillips curve}

The problem of the behavioral firm is then to maximize

$$
\sum_{k=0}^{\infty} \theta^{k} \mathbb{E}_{t}^{B R}\left[\Lambda_{t, t+k}\left(P_{t}^{*} Y_{t+k \mid t}-\Psi_{t+k}\left(Y_{t+k \mid t}\right)\right)\right]
$$

subject to the sequence of demand constraints

$$
Y_{t+k \mid t}=\left(\frac{P_{t}^{*}}{P_{t+k}}\right)^{-\varepsilon} Y_{t+k}
$$

where $\Lambda_{t, t+k}=\beta^{k}\left(C_{t+k} / C_{t}\right)^{-\gamma}\left(P_{t+k} / P_{t}\right)$ is the stochastic discount factor in nominal terms, $\Psi_{t+k}($.$) is the cost function, and Y_{t+k \mid t}$ denotes the output in period $t+k$ for a firm that last reset its price in period $t$.

The FOC of the problem is the following:

$$
\sum_{k=0}^{\infty} \theta^{k} \mathbb{E}_{t}^{B R}\left[\Lambda_{t, t+k} Y_{t+k \mid t}\left(P_{t}^{*}-\mathcal{M} \psi_{t+k \mid t}\right)\right]=0
$$

where $\mathcal{M}=\frac{\varepsilon}{\varepsilon-1}$ is the desired or frictionless markup.

By dividing Eq. 50 by $P_{t-1}$ and defining $\Pi_{t, t+k}=\frac{P_{t+k}}{P_{t}}$ and $M C_{t+k / t}=\frac{\psi_{t+k \mid t}}{P_{t+k}}$, we obtain the following

$$
\sum_{k=0}^{\infty} \theta^{k} \mathbb{E}_{t}^{B R}\left[\Lambda_{t, t+k} Y_{t+k \mid t}\left(\frac{P_{t}^{*}}{P_{t-1}}-\mathcal{M} M C_{t+k / t} \Pi_{t-1, t+k}\right)\right]=0
$$


We define the steady state of $\Lambda_{t, t+k}$ as $\beta^{k}, Y_{t+k \mid t}$ as $Y, \frac{P_{t}^{*}}{P_{t-1}}$ as $1, M C_{t+k / t}$ as $\frac{1}{\mathcal{M}}$, and $\Pi_{t-1, t+k}$ as 1 . These defined steady states allow us to expand the FOC (Eq. 51) as follows

$$
\sum_{k=0}^{\infty}(\beta \theta)^{k} \mathbb{E}_{t}^{B R}\left[p_{t}^{*}-p_{t-1}-\left(\widehat{m c}_{t+k / t}+p_{t+k}-p_{t-1}\right)\right]=0
$$

with small letters denoting the logarithm of capital letters $p_{t}=\ln P_{t}$ and hat indicating the deviation with respect to the steady state $\widehat{m c}_{t+k / t}=m c_{t+k / t}-m c$, where $m c_{t+k / t}=\ln M C_{t+k / t}$, and $m c=-\mu$, where $\mu=\ln \mathcal{M}$.

By simplifying Eq. 52 we obtain

$$
p_{t}^{*}-p_{t-1}=(1-\beta \theta) \sum_{k=0}^{\infty}(\beta \theta)^{k} \mathbb{E}_{t}^{B R}\left[\widehat{m c}_{t+k / t}+p_{t+k}-p_{t-1}\right]
$$

By rearranging the terms of Eq. 53, we obtain

$$
p_{t}^{*}=\mu+(1-\beta \theta) \sum_{k=0}^{\infty}(\beta \theta)^{k} \mathbb{E}_{t}^{B R}\left[m c_{t+k / t}+p_{t+k}\right]
$$

The (log) marginal cost can be expressed as

$$
m c_{t+k \mid t}=m c_{t+k}-\frac{\alpha \epsilon}{1-\alpha}\left(p_{t}^{*}-p_{t+k}\right)
$$

We replace Eq. 55 in Eq. 53 and find

$$
p_{t}^{*}-p_{t-1}=(1-\beta \theta) \sum_{k=0}^{\infty}(\beta \theta)^{k} \mathbb{E}_{t}^{B R}\left[\widehat{m c}_{t+k}-\frac{\alpha \epsilon}{1-\alpha}\left(p_{t}^{*}-p_{t+k}\right)+p_{t+k}-p_{t-1}\right]
$$

Rearranging terms leads to the following expression

$$
p_{t}^{*}-p_{t-1}=(1-\beta \theta) \sum_{k=0}^{\infty}(\beta \theta)^{k} \mathbb{E}_{t}^{B R}\left[\Theta \widehat{m c}_{t+k}+p_{t+k}-p_{t-1}\right]
$$

where $\Theta=\frac{1-\alpha}{1-\alpha+\alpha \epsilon}$.

Eq. 57 can be expressed as

$$
p_{t}^{*}-p_{t-1}=(1-\beta \theta) \Theta \sum_{k=0}^{\infty}(\beta \theta)^{k} \mathbb{E}_{t}^{B R}\left[\widehat{m c}_{t+k}\right]+\sum_{k=0}^{\infty}(\beta \theta)^{k} \mathbb{E}_{t}^{B R}\left[\pi_{t+k}\right]
$$

We recall the term structure of expectations from Gabaix (2019): $\mathbb{E}_{t}^{B R}\left[\pi_{t+k}\right]=$ $m_{\pi}^{f} \bar{m}^{k} \mathbb{E}_{t}\left[\pi_{t+k}\right]$ and $\mathbb{E}_{t}^{B R}\left[\widehat{m c}_{t+k}\right]=m_{x}^{f} \bar{m}^{k} \mathbb{E}_{t}\left[\widehat{m c}_{t+k}\right]$, where $\bar{m}$ is the general myopia 
to the evolution of the economy's state, $m_{\pi}^{f}$ is the myopia to prices, and $m_{x}^{f}$ is the myopia related to output. Hence, Eq. 58 can be rewritten as

$$
p_{t}^{*}-p_{t-1}=(1-\beta \theta) \Theta \sum_{k=0}^{\infty}(\beta \theta)^{k} m_{x}^{f} \bar{m}^{k} \mathbb{E}_{t}\left[\widehat{m c}_{t+k}\right]+\sum_{k=0}^{\infty}(\beta \theta)^{k} m_{\pi}^{f} \bar{m}^{k} \mathbb{E}_{t}\left[\pi_{t+k}\right]
$$

By writing this equation as a difference equation, we find

$$
p_{t}^{*}-p_{t-1}=\beta \theta \bar{m} \mathbb{E}_{t}\left[p_{t+1}^{*}-p_{t}\right]+(1-\beta \theta) \Theta m_{x}^{f} \widehat{m c}_{t}+m_{\pi}^{f} \pi_{t}
$$

We combine Eq. 60 with $\pi_{t}=(1-\theta)\left(p_{t}^{*}-p_{t-1}\right)$ and obtain

$$
\pi_{t}=\frac{\beta \theta \bar{m}}{1-(1-\theta) m_{\pi}^{f}} \mathbb{E}_{t}\left[\pi_{t+1}\right]+\frac{(1-\theta)(1-\beta \theta) \Theta m_{x}^{f}}{1-(1-\theta) m_{\pi}^{f}} \widehat{m c}_{t}
$$

We express the real marginal cost, $m c_{t}$, as a function of the output gap, $\tilde{y}_{t}$. Notice that the real marginal cost is defined in terms of the real wage and marginal productivity of labor:

$$
m c_{t}=w_{t}-m p n_{t}
$$

Using the facts that the real wage equals the marginal rate of substitution between consumption and labor and that the marginal productivity can be derived from Eq. 11, expression Eq. 62 can be written as

$$
m c_{t}=\left(\gamma y_{t}+\phi n_{t}\right)-\left(y_{t}-n_{t}\right)-\ln (1-\alpha)
$$

We use the production function Eq. 11 to eliminate $n_{t}$ from Eq. 63, and we obtain

$$
m c_{t}=\left(\gamma+\frac{\phi+\alpha}{1-\alpha}\right) y_{t}-\frac{1+\phi}{1-\alpha} a_{t}-\ln (1-\alpha)
$$

Writing Eq. 64 in the flexible price economy yields

$$
m c=\left(\gamma+\frac{\phi+\alpha}{1-\alpha}\right) y_{t}^{n}-\frac{1+\phi}{1-\alpha} a_{t}-\ln (1-\alpha)
$$

where $y_{t}^{n}$ is the natural output. Finally, by subtracting Eq. 65 from Eq. 64, we obtain

$$
\widehat{m c}_{t}=\left(\gamma+\frac{\phi+\alpha}{1-\alpha}\right)\left(y_{t}-y_{t}^{n}\right)=\left(\gamma+\frac{\phi+\alpha}{1-\alpha}\right) \tilde{y}_{t}
$$

Finally, by replacing Eq. 66 in the price setting Eq. 61, we obtain

$$
\pi_{t}=\frac{\beta \theta \bar{m}}{1-(1-\theta) m_{\pi}^{f}} \mathbb{E}_{t}\left[\pi_{t+1}\right]+\frac{(1-\theta)(1-\beta \theta) \Theta m_{x}^{f}}{1-(1-\theta) m_{\pi}^{f}}\left(\gamma+\frac{\phi+\alpha}{1-\alpha}\right) \tilde{y}_{t}
$$


The resulting behavioral Phillips curve is

$$
\pi_{t}=\beta M^{f} \mathbb{E}_{t}\left[\pi_{t+1}\right]+\kappa \tilde{y}_{t}
$$

where $M^{f}=\frac{\theta \bar{m}}{1-(1-\theta) m_{\pi}^{f}}$ and $\kappa=\frac{(1-\theta)(1-\beta \theta) \Theta m_{x}^{f}}{1-(1-\theta) m_{\pi}^{f}}\left(\gamma+\frac{\phi+\alpha}{1-\alpha}\right)$.

Note that if we consider the rational case, where $m_{x}^{f}=m_{\pi}^{f}=\bar{m}=1$, we end up with the usual Phillips curve as in Galí (2015).

\section{A.3 Natural output}

The marginal cost of a firm is defined as

$$
\mu_{t}=-w_{t}-m p n_{t}
$$

where $m p n_{t}$ is the marginal productivity of labor. Recall that the marginal rate of substitution between labor and consumption equals the real wage, which can be expressed as

$$
-\frac{U_{n, t}}{U_{c, t}}=\frac{W_{t}}{P_{t}}
$$

Taking logs, we obtain $w_{t}=\phi n_{t}+\gamma c_{t}$.

For the marginal productivity of labor in logs, we have

$$
m p n_{t}=a-\alpha n_{t}+\ln (1-\alpha)
$$

and because the production function takes the form $y_{t}=a_{t}+(1-\alpha) n_{t}$, we can express the marginal cost formula in terms of output and a technological factor as

$$
\mu_{t}=-\left(\gamma+\frac{\phi+\alpha}{1-\alpha}\right) y_{t}-\frac{1+\phi}{1-\alpha} a_{t}-\ln (1-\alpha)
$$

By expressing this formula in the flexible price economy, we obtain

$$
\mu=-\left(\gamma+\frac{\phi+\alpha}{1-\alpha}\right) y_{t}^{n}-\frac{1+\phi}{1-\alpha} a_{t}-\ln (1-\alpha)
$$

where $\mu=\ln \left(\frac{\varepsilon}{\varepsilon-1}\right)$ is the marginal cost prevailing under flexible prices and $y_{t}^{n}$ is the natural output.

By solving for $y_{t}^{n}$, we obtain the expression for natural output as

$$
y_{t}^{n}=\frac{1+\phi}{\phi+\alpha+\gamma(1-\alpha)} a_{t}+\frac{(1-\alpha)(-\mu+\ln (1-\alpha))}{\phi+\alpha+\gamma(1-\alpha)}
$$




\section{A.4 Efficient interest rate}

The IS curve Eq. 75 is written as

$$
\hat{y}_{t}=M \mathbb{E}_{t}\left[\hat{y}_{t+1}\right]-\sigma\left(i_{t}-\mathbb{E}_{t}\left[\pi_{t+1}\right]-r_{t}^{n}\right)
$$

Note that the definitions of the output gap, $\hat{y}_{t}$, and the relevant output gap, $x_{t}$, are

$$
\begin{aligned}
& \hat{y}_{t}=y_{t}-y_{t}^{n} \\
& x_{t}=y_{t}-y_{t}^{e}
\end{aligned}
$$

where $y_{t}^{n}$ is the natural output and $y_{t}^{e}$ is the efficient output.

By employing those definitions, we can write the IS curve Eq. 19 as

$$
y_{t}-y_{t}^{n}=M \mathbb{E}_{t}\left[y_{t+1}-y_{t+1}^{n}\right]-\sigma\left(i_{t}-\mathbb{E}_{t}\left[\pi_{t+1}\right]-r_{t}^{n}\right)
$$

which is equivalent to

$$
y_{t}-y_{t}^{e}+y_{t}^{e}-y_{t}^{n}=M \mathbb{E}_{t}\left[y_{t+1}-y_{t+1}^{e}+y_{t+1}^{e}-y_{t+1}^{n}\right]-\sigma\left(i_{t}-\mathbb{E}_{t}\left[\pi_{t+1}\right]-r_{t}^{n}\right)
$$

The welfare-relevant output gap is

$$
x_{t}+y_{t}^{e}-y_{t}^{n}=M \mathbb{E}_{t}\left[x_{t+1}+y_{t+1}^{e}-y_{t+1}^{n}\right]-\sigma\left(i_{t}-\mathbb{E}_{t}\left[\pi_{t+1}\right]-r_{t}^{n}\right)
$$

which leads us to the following expression

$$
x_{t}=M \mathbb{E}_{t}\left[x_{t+1}\right]+M \mathbb{E}_{t}\left[y_{t+1}^{e}-y_{t+1}^{n}\right]-\left(y_{t}^{e}-y_{t}^{n}\right)-\sigma\left(i_{t}-\mathbb{E}_{t}\left[\pi_{t+1}\right]-r_{t}^{n}\right)
$$

Hence, we obtain

$$
x_{t}=M \mathbb{E}_{t}\left[x_{t+1}\right]-\sigma\left(i_{t}-\mathbb{E}_{t}\left[\pi_{t+1}\right]-r_{t}^{e}\right)
$$

where

$$
r_{t}^{e}=r_{t}^{n}+\frac{1}{\sigma}\left(M \mathbb{E}_{t}\left[y_{t+1}^{e}-y_{t+1}^{n}\right]-\left(y_{t}^{e}-y_{t}^{n}\right)\right)
$$

By taking Eq. 83 in deviation from its flexible price economy counterpart, we obtain an expression for the efficient interest rate in deviation form such as

$$
\begin{aligned}
r_{t}^{e}-r_{t}^{n}= & {\left[r_{t}^{n}+\frac{1}{\sigma}\left(M \mathbb{E}_{t}\left[y_{t+1}^{e}-y_{t+1}^{n}\right]-\left(y_{t}^{e}-y_{t}^{n}\right)\right)\right] } \\
& -\left[r_{t}^{n}+\frac{1}{\sigma}\left(M \mathbb{E}_{t}\left[y_{t+1}^{n}-y_{t+1}^{n}\right]-\left(y_{t}^{n}-y_{t}^{n}\right)\right)\right]
\end{aligned}
$$


Considering the notation $\hat{v}=v-v^{n}$, Eq. 84 can be simplified to

$$
\hat{r}_{t}^{e}=\frac{1}{\sigma}\left(M \mathbb{E}_{t}\left[\hat{y}_{t+1}^{e}\right]-\hat{y}_{t}^{e}\right)
$$

\section{A.5 Welfare loss}

The Taylor expansion of the utility function $U_{t}$ defined in Eq. 1 is the following:

$U_{t}-U=U_{c} c\left(\frac{c_{t}-c}{c}\right)+\frac{1}{2} U_{c c} c^{2}\left(\frac{c_{t}-c}{c}\right)^{2}+U_{n} N\left(\frac{N_{t}-N}{N}\right)+\frac{1}{2} U_{n n} N^{2}\left(\frac{N_{t}-N}{N}\right)^{2}+\Theta\left(Z^{3}\right)$

where $\Theta\left(Z^{3}\right)$ represents the terms up to the power of 3 and null cross variables derivatives due to the separability of our utility function.

To further develop the Eq. 86, we use the fact that $U_{c c}=-\gamma \frac{1}{c} U_{c}$ and $U_{n n}=$ $-\phi \frac{1}{N} U_{n}$. Moreover, note that for any variable $z_{t}$, we have $\frac{z_{t}-z}{z}=\hat{z}_{t}+\frac{1}{2} \hat{z}_{t}^{2}$.

Taking into account all of this, Eq. 86 becomes

$$
U_{t}-U=U_{c} c\left(\hat{c}_{t}+\frac{1-\gamma}{2} \hat{c}_{t}^{2}\right)+U_{n} N\left(\hat{n}_{t}+\frac{1+\phi}{2} \hat{n}_{t}^{2}\right)+\Theta\left(Z^{3}\right)
$$

We express $\hat{n}_{t}$ in terms of $\tilde{y}_{t}$ (remember that $\tilde{y}_{t}$ is our notation for the output gap from Section 2.1). Using $Y_{t}(i)=\left(\frac{P_{t}(i)}{P_{t}}\right)^{-\epsilon} Y_{t}$ and $P_{t}=\left(\int_{0}^{1} P_{t}(i)^{1-\epsilon} d i\right)^{\frac{1}{1-\epsilon}}$, we have

$$
\begin{aligned}
N_{t} & =\int_{0}^{1} N_{t}(i) d i \\
& =\int_{0}^{1}\left(\frac{Y_{t}(i)}{A_{t}}\right)^{\frac{1}{1-\alpha}} d i \\
& =\left(\frac{Y_{t}}{A_{t}}\right)^{\frac{1}{1-\alpha}} \int_{0}^{1}\left(\frac{P_{t}(i)}{P_{t}}\right)^{-\frac{\epsilon}{1-\alpha}} d i
\end{aligned}
$$

In terms of log deviations, this expression can be written as

$$
(1-\alpha) \hat{n}_{t}=\tilde{y}_{t}-a_{t}+d_{t}
$$

where $d_{t}=(1-\alpha) \ln \int_{0}^{1}\left(\frac{P_{t}(i)}{P_{t}}\right)^{-\frac{\epsilon}{1-\alpha}} d i$. It follows from Lemma 1 (Galí (2015), chapter 4) that

$$
d_{t}=\frac{\epsilon}{2 \Theta} \operatorname{var}_{i}\left\{p_{t}(i)\right\}
$$

Returning to our Taylor expansion Eq. 87 and using the fact that $\hat{c}_{t}=\tilde{y}_{t}$, we 
obtain

$$
U_{t}-U=U_{c} c\left(\tilde{y}_{t}+\frac{1-\gamma}{2} \tilde{y}_{t}^{2}\right)+\frac{U_{n} N}{1-\alpha}\left(\tilde{y}_{t}+\frac{\epsilon}{2 \Theta} \operatorname{var}_{i}\left\{p_{t}(i)\right\}+\frac{1+\phi}{2(1-\alpha)}\left(\tilde{y}_{t}-a_{t}\right)^{2}\right)
$$

The efficiency of the steady state implies

$$
-\frac{U_{n}}{U_{c}}=M P N=(1-\alpha) \frac{Y}{N}
$$

By combining the previous two equations we find

$$
\frac{U_{t}-U}{U_{c} c}=\tilde{y}_{t}+\frac{1-\gamma}{2} \tilde{y}_{t}^{2}-\left(\tilde{y}_{t}+\frac{\epsilon}{2 \Theta} \operatorname{var}_{i}\left\{p_{t}(i)\right\}+\frac{1+\phi}{2(1-\alpha)}\left(\tilde{y}_{t}-a_{t}\right)^{2}\right)
$$

As in Galí (2015), we can consider that the product of $\Phi$ with second-order terms is null under the assumption of small distortions. We obtain

$$
\begin{aligned}
\frac{U_{t}-U}{U_{c} c} & =-\frac{1}{2}\left[\frac{\epsilon}{\Theta} \operatorname{var}_{i}\left\{p_{t}(i)\right\}-(1-\gamma) \tilde{y}_{t}^{2}+\frac{1+\phi}{1-\alpha}\left(\tilde{y}_{t}-a_{t}\right)^{2}\right] \\
& =-\frac{1}{2}\left[\frac{\epsilon}{\Theta} \operatorname{var}_{i}\left\{p_{t}(i)\right\}+\left(\gamma+\frac{\phi+\alpha}{1-\alpha}\right) \tilde{y}_{t}^{2}-2\left(\frac{1+\phi}{1-\alpha}\right) \tilde{y}_{t} a_{t}\right]
\end{aligned}
$$

Using the fact that $\hat{y}_{t}^{e}=\frac{1+\phi}{\gamma(1-\alpha)+\phi+\alpha} a_{t}$, we obtain

$$
\frac{U_{t}-U}{U_{c} c}=-\frac{1}{2}\left[\frac{\epsilon}{\Theta} \operatorname{var}_{i}\left\{p_{t}(i)\right\}+\left(\gamma+\frac{\phi+\alpha}{1-\alpha}\right)\left(\tilde{y}_{t}-\hat{y}_{t}^{e}\right)^{2}\right]
$$

The welfare loss is expressed as a fraction of the steady-state consumption

$$
\begin{aligned}
\mathbb{W} & =-\mathbb{E}_{0} \sum_{t=0}^{\infty} \beta^{t}\left(\frac{U_{t}-U}{U_{c} c}\right) \\
& =-\mathbb{E}_{0} \sum_{t=0}^{\infty} \beta^{t}\left[-\frac{1}{2}\left(\frac{\epsilon}{\Theta} \operatorname{var}_{i}\left\{p_{t}(i)\right\}+\left(\gamma+\frac{\phi+\alpha}{1-\alpha}\right)\left(\tilde{y}_{t}-\hat{y}_{t}^{e}\right)^{2}\right)\right]
\end{aligned}
$$

Assuming that $x_{t}=y_{t}-y_{t}^{e}=\tilde{y}_{t}-\hat{y}_{t}^{e}$ and by applying Lemma 2 (Galí (2015), chapter 4), we find the welfare loss expression

$$
\mathbb{W}=-\mathbb{E}_{0} \sum_{t=0}^{\infty} \beta^{t}\left[-\frac{1}{2}\left(\frac{\epsilon}{\Theta} \frac{\theta}{(1-\beta \theta)(1-\theta)} \pi_{t}^{2}+\left(\gamma+\frac{\phi+\alpha}{1-\alpha}\right) x_{t}^{2}\right)\right]
$$




\section{B Robustness check}

This section presents our results under the alternative model and myopia calibrations.

\section{B.1 Model calibrations}

Table 7 presents the different model calibrations considered in the following robustness analysis.

$\begin{array}{rcccccc}\text { Calibration name } & \beta & \gamma & \phi & \epsilon & \alpha & \theta \\ \text { Galí }(2008) & 0.99 & 1 & 1 & 6 & 1 / 3 & 0.66 \\ \text { Relative risk aversion } & 0.99 & 2 & 1 & 6 & 1 / 3 & 0.66 \\ \text { Frisch elasticity } & 0.99 & 1 & 5 & 6 & 1 / 3 & 0.66 \\ \text { Constant return to scale } & 0.99 & 1 & 1 & 6 & 0 & 0.66 \\ \text { Sticky prices } & 0.99 & 1 & 1 & 6 & 1 / 3 & 3 / 4 \\ \text { Time preferences } & 0.996 & 1 & 1 & 6 & 1 / 3 & 0.66 \\ \text { Demand elasticity } & 0.99 & 1 & 1 & 9 & 1 / 3 & 0.66 \\ \text { Galí }(2015) & 0.996 & 2 & 5 & 9 & 1 / 3 & 3 / 4\end{array}$

Table 7: Calibration of the model parameters used for the robustness checks.

Fig. 4 to Fig. 7 present the impulse response of inflation, output, interest rate and price level under commitment, respectively, over the different calibrations presented in Table 7. Fig. 8 to Fig. 11 present the impulse response of inflation, output, interest rate and price level under commitment, respectively, over the different calibrations presented in Table 7 .

Impulse responses functions for optimal simple rules under each calibration are available upon request. Welfare heatmaps for commitment and discretion under the different model calibrations (Table 7) are presented in Table 8. Welfare heatmaps of optimal simple rules under different model calibrations are available upon request.

The impulse response functions lead to similar conclusions as in Sections 4.2 and 5.2, whatever the model calibration chosen.

Recall from section 2.2 the discussion about the effect of constant returns to scale; it is worth noting that when $\alpha \neq 0$, the trade-off between inflation and output worsens, and the central bank acts aggressively in order to accommodate the cost-push shock as it is clear from the Figures below when comparing the baseline calibration to the constant returns to scale calibration $\alpha=0$.

Table 8 reveals that under different model calibrations, myopia does not necessarily increase welfare losses. Interestingly, our previous results hold. Increasing the Frisch elasticity or decreasing the constant return to scale leads to lower welfare losses whatever the type of myopia. Under discretion and optimal simple rules, the 

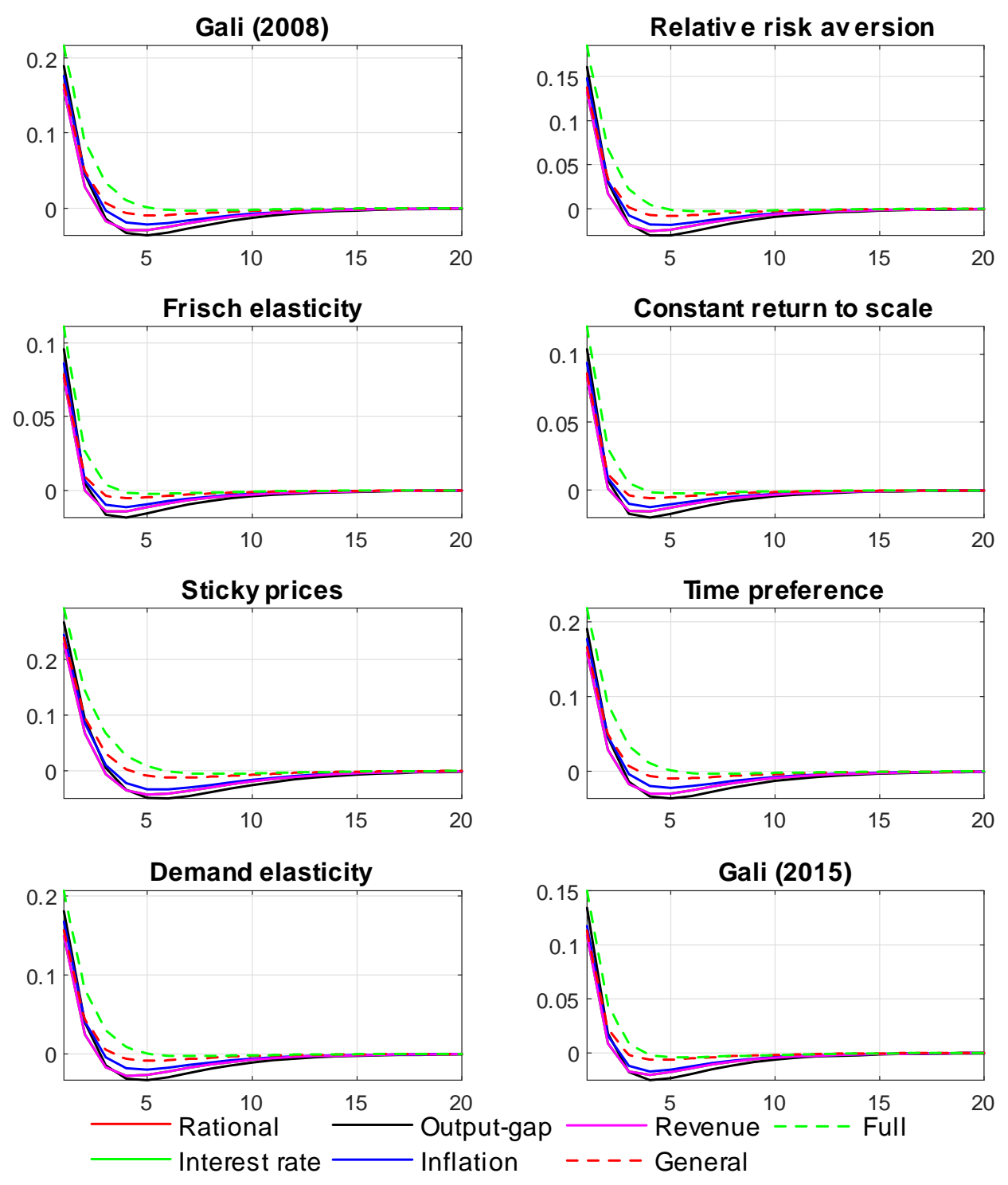

Figure 4: Impulse response functions of inflation following a 1\% cost-push shock under commitment for each model and myopia calibration.

welfare-improving abilities of the general myopia are clear and robust. This result is not clear under commitment for such myopia levels (85\%), but extreme myopia values demonstrate the robustness of this result (Appendix B.2). 

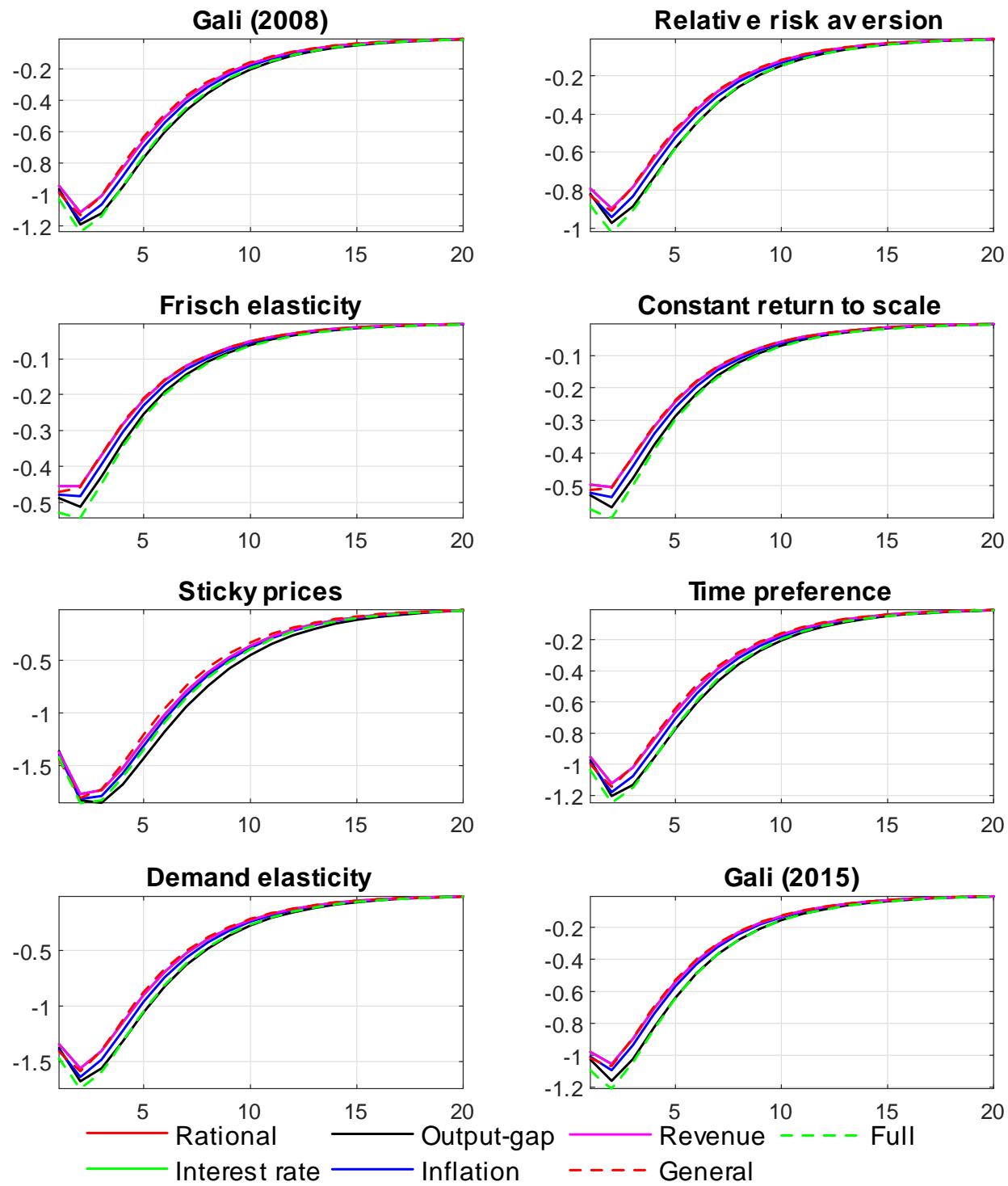

Figure 5: Impulse response functions of output following a $1 \%$ cost-push shock under commitment for each model and myopia calibration. 

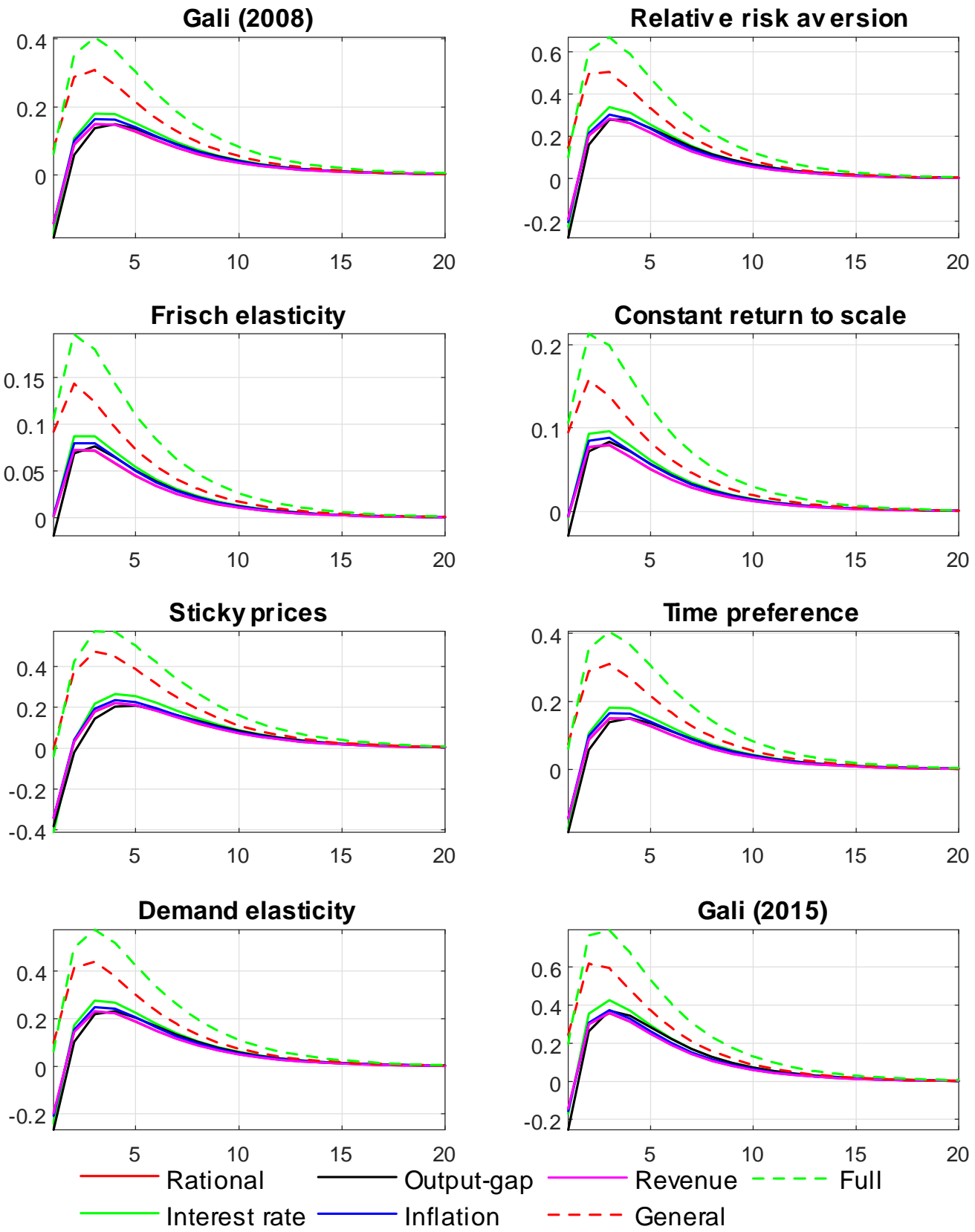

Figure 6: Impulse response functions of interest rate following a 1\% cost-push shock under commitment for each model and myopia calibration. 

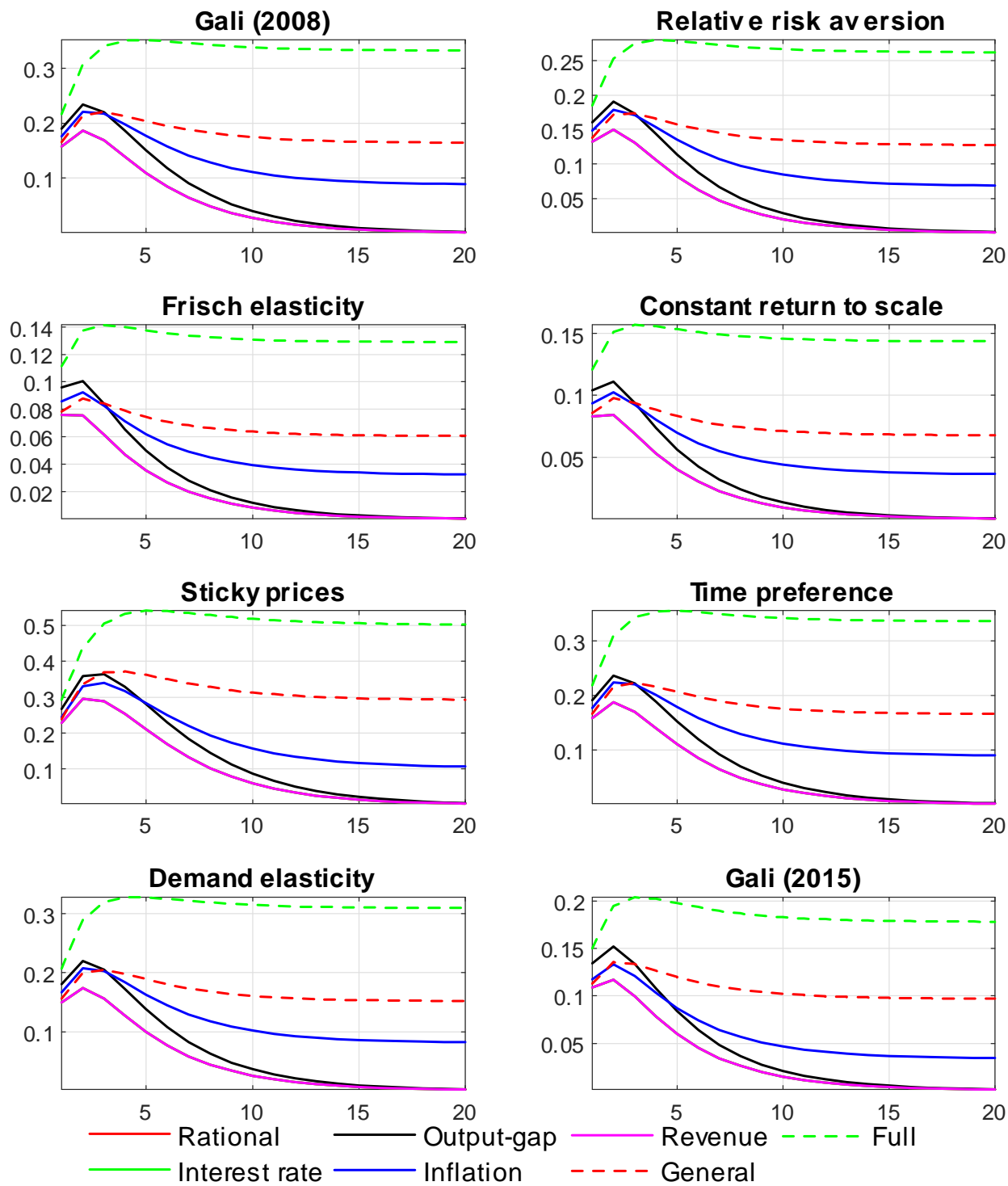

Figure 7: Impulse response functions of price level following a 1\% cost-push shock under commitment for each model and myopia calibration. 

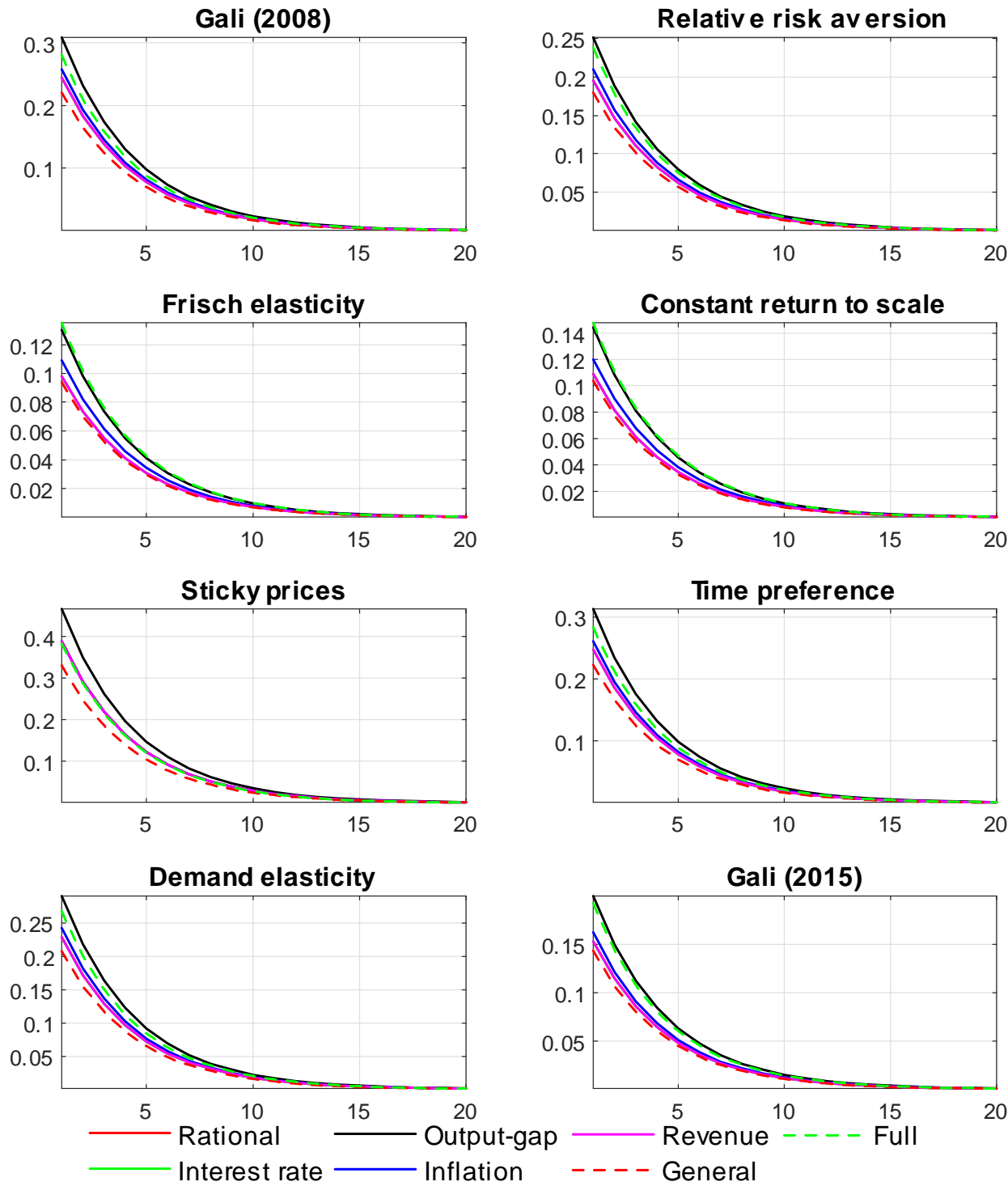

Figure 8: Impulse response functions of inflation following a $1 \%$ cost-push shock under discretion for each model and myopia calibration. 

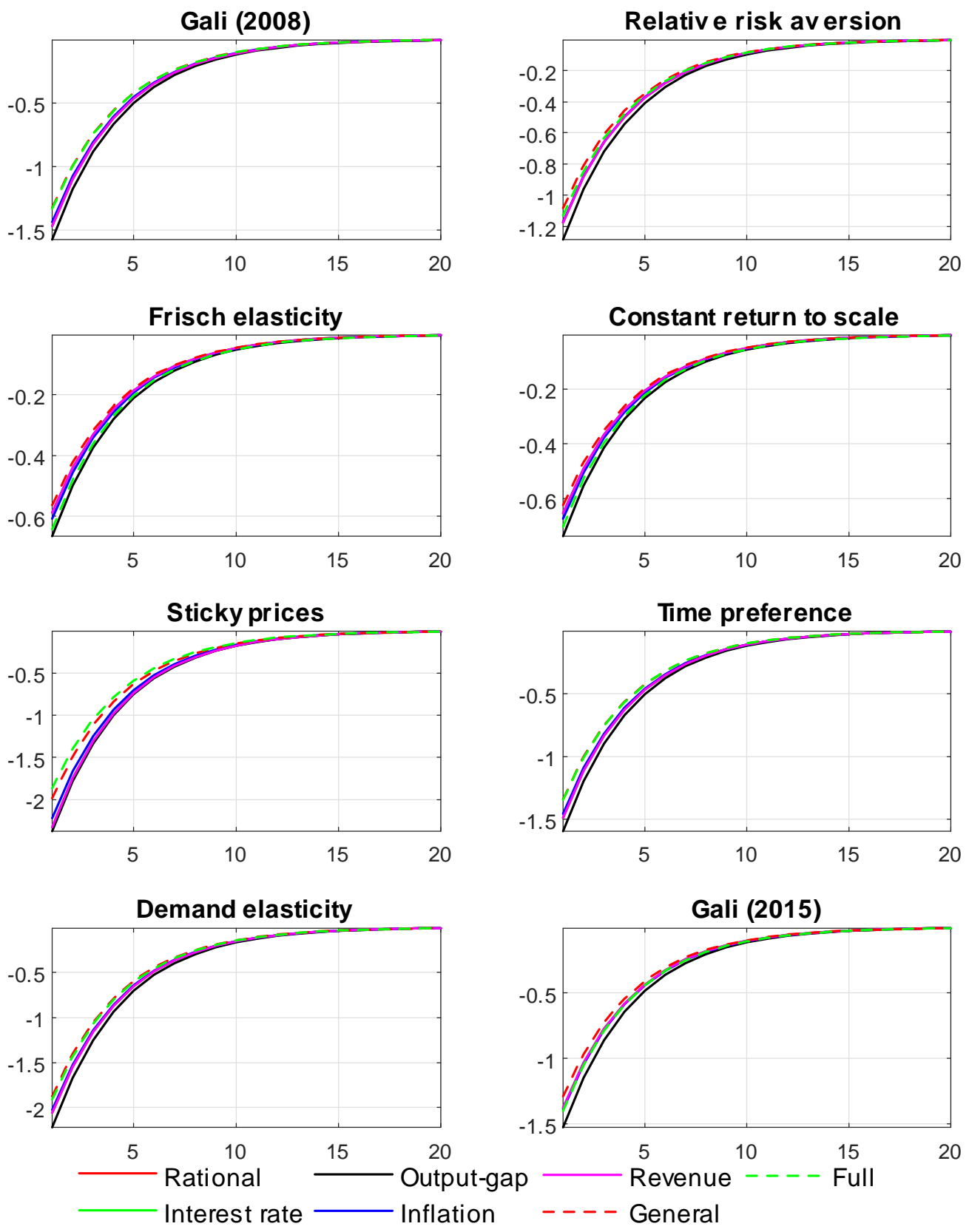

Figure 9: Impulse response functions of output following a 1\% cost-push shock under discretion for each model and myopia calibration. 

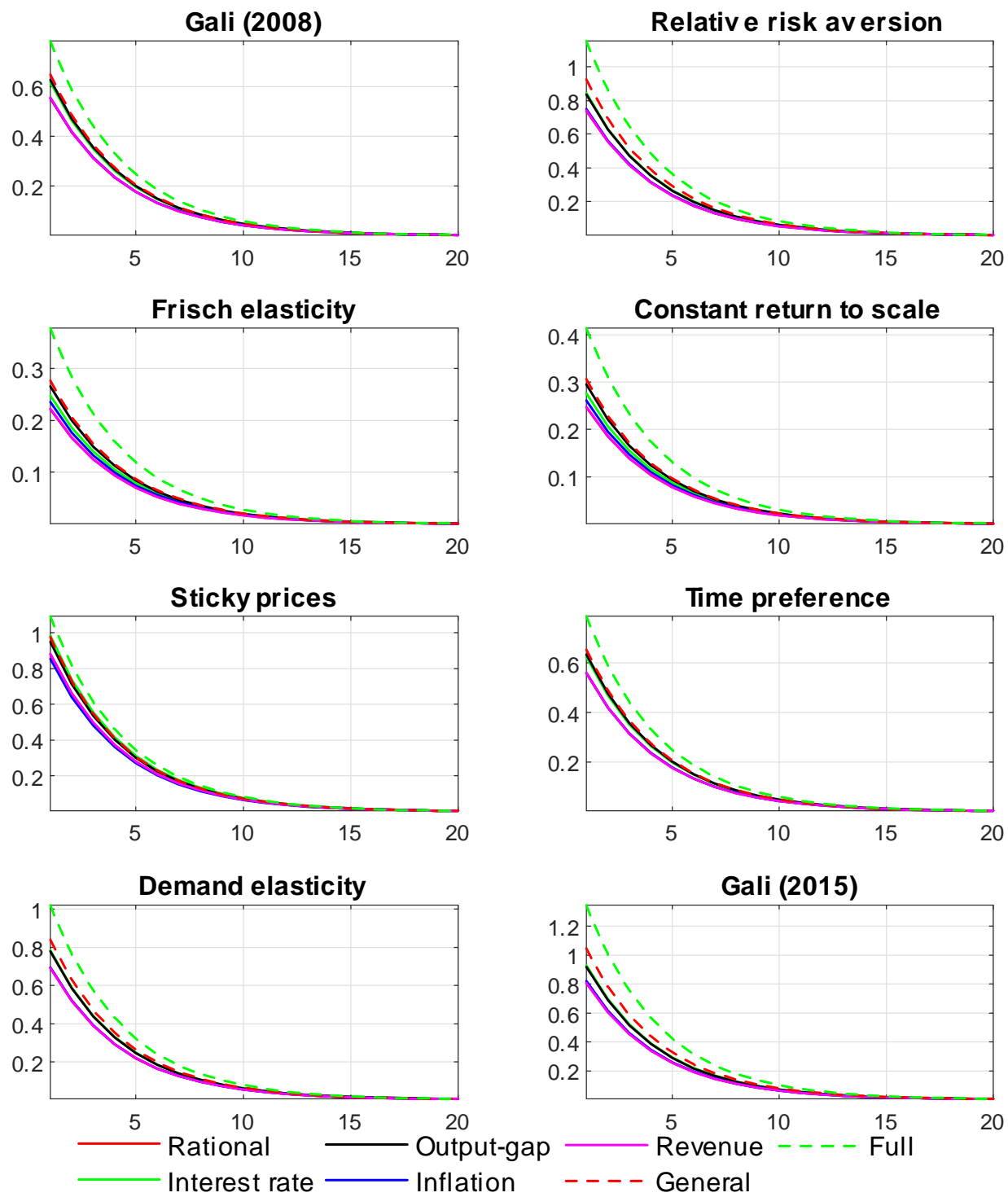

Figure 10: Impulse response functions of interest rate following a 1\% cost-push shock under discretion for each model and myopia calibration. 

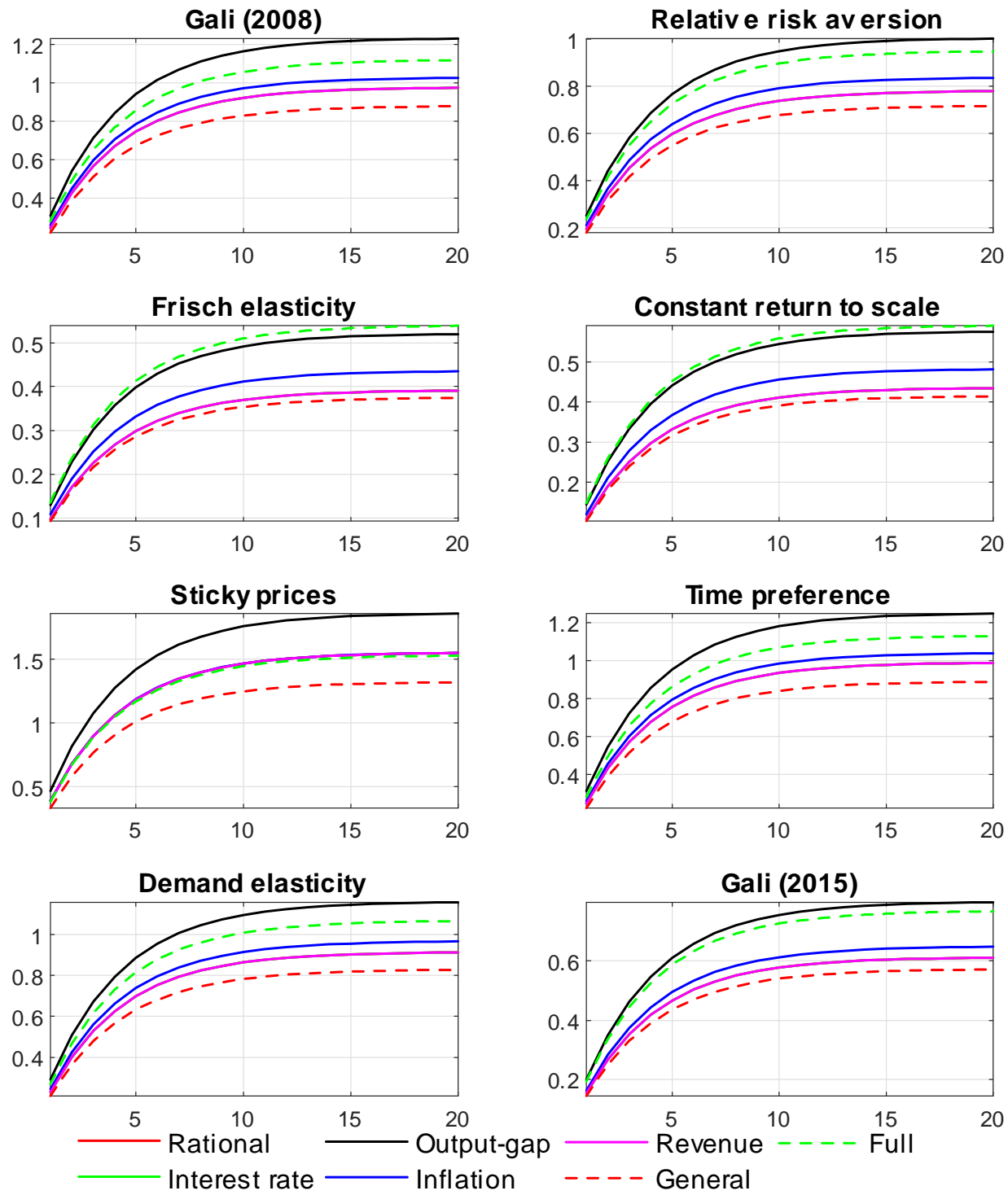

Figure 11: Impulse response functions of price level following a 1\% cost-push shock under discretion for each model and myopia calibration. 


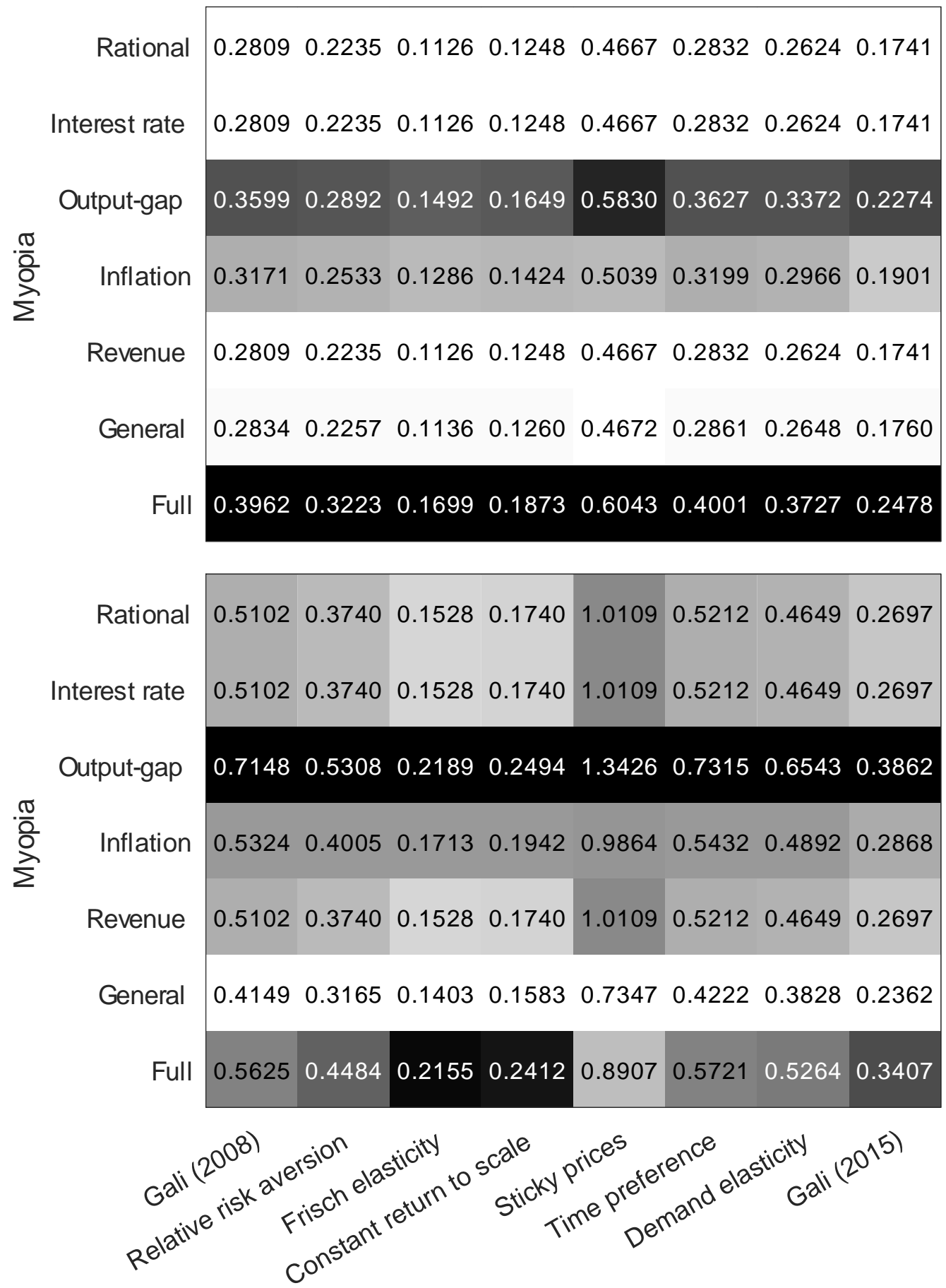

Table 8: Welfare losses under commitment (top) and discretion (bottom) for each calibration. 


\section{B.2 Myopia calibrations}

The different myopia cases considered in this section are presented in Table 9 .

\begin{tabular}{|c|c|c|c|c|c|c|c|}
\hline \multicolumn{8}{|c|}{ Models } \\
\hline No myopia & & & $\mathrm{Myc}$ & & & & \\
\hline Rational & Interest rate & Output gap & Inflation & Revenue & General & Full & Extreme \\
\hline 1 & 0.2 & 1 & 1 & 1 & 1 & 0.2 & 0.01 \\
\hline 1 & 1 & 0.2 & 1 & 1 & 1 & 0.2 & 0.01 \\
\hline 1 & 1 & 1 & 0.2 & 1 & 1 & 0.2 & 0.01 \\
\hline 1 & 1 & 1 & 1 & 0.2 & 1 & 0.2 & 0.01 \\
\hline 1 & 1 & 1 & 1 & 1 & 0.2 & 0.2 & 0.01 \\
\hline
\end{tabular}

Table 9: Calibration of the myopia parameters used for the simulations.

Table 9 presents more pronounced myopic agents with approximately $80 \%$ myopia and an extreme case with an almost fully myopic agent (99\%). The impulse response functions resulting from the calibration presented in Table 9 are presented in the case of commitment (Fig. 12) and discretion (Fig. 13). The optimal simple rule cases are available upon request.
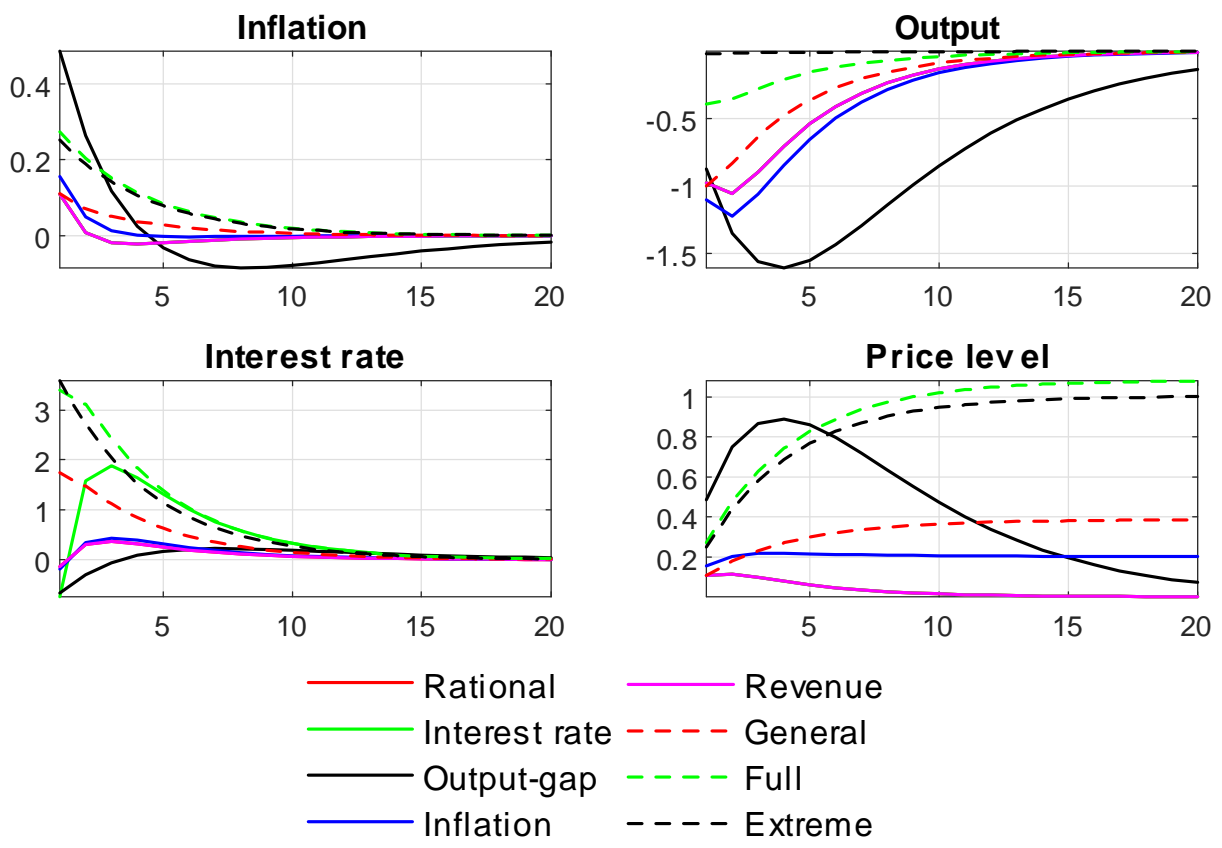

Figure 12: Impulse response functions of inflation, price level, output and interest rate following a $1 \%$ cost-push shock under commitment for each model calibration (Table 9).

Table 10 presents the welfare losses under the standard calibration Galí (2015) for commitment and discretion. Here again the results for the optimal simple rule cases are available upon request. The results under the different calibrations presented in Table 9 are also available upon request. 

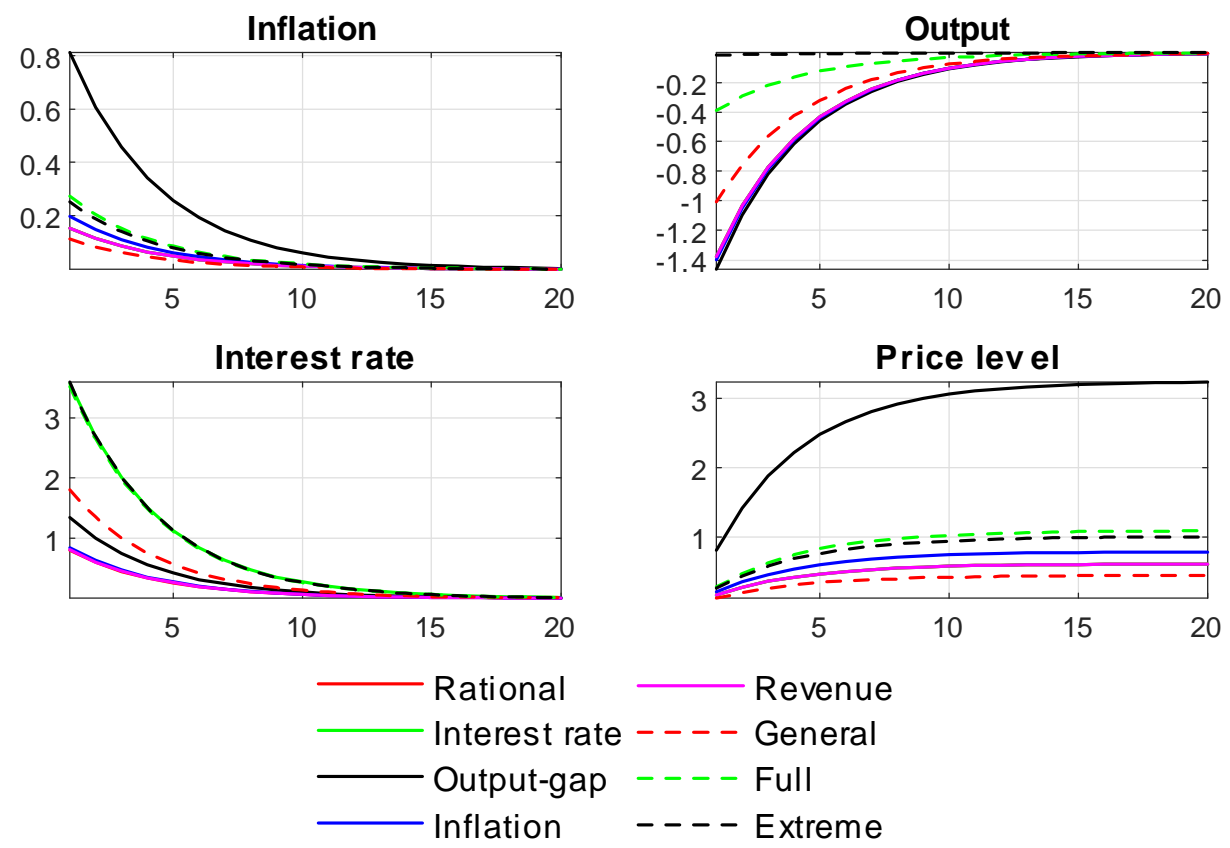

Figure 13: Impulse response functions of inflation, price level, output and interest rate following a $1 \%$ cost-push shock under commitment for each model calibration (Table 9).

\begin{tabular}{rccccccc} 
& \multicolumn{8}{c}{ Myopia } \\
\cline { 2 - 8 } & Interest rate & Output gap & Inflation & Revenue & General & Full & Extreme \\
Commitment & 0.174 & 1.446 & 0.257 & 0.174 & 0.143 & 0.372 & 0.302 \\
Discretion & 0.270 & 3.357 & 0.348 & 0.270 & 0.145 & 0.372 & 0.302
\end{tabular}

Table 10: Welfare losses under commitment and discretion for each myopia calibration.

Table 10 shows that the welfare losses under discretion are always higher than under commitment, except under full and extreme myopia. Interestingly, the general myopia case leads to the best welfare losses under commitment and discretion, confirming our result that myopia can also improve welfare losses.

From these robustness analyses, one can conclude that there exists a general myopia level that improves the welfare losses whatever the chosen commitment, discretion or optimal simple rule regime. 